\title{
Predominance of deterministic microbial community dynamics in salterns exposed to different light intensities
}

Tomeu Viver ${ }^{1}$, Luis H. Orellana ${ }^{2}$, Sara Díaz ${ }^{1}$, Mercedes Urdiain ${ }^{1}$, María Dolores RamosBarbero $^{3}$, José E. González-Pastor ${ }^{4}$, Aharon Oren ${ }^{5}$, Janet K. Hatt ${ }^{2}$, Rudolf Amann ${ }^{6}$, Josefa Antón $^{3}$, Konstantinos T. Konstantinidis ${ }^{2}$, Ramon Rosselló-Móra ${ }^{1}$

\author{
Affiliations \\ ${ }^{1}$ Marine Microbiology Group, Department of Animal and Microbial Biodiversity, Mediterranean \\ Institute for Advanced Studies (IMEDEA, CSIC-UIB), Esporles, Spain \\ 2 School of Civil \& Environmental Engineering, Georgia Institute of Technology, Atlanta, \\ Georgia, USA \\ ${ }^{3}$ Department of Physiology, Genetics and Microbiology, University of Alicante, Alicante, Spain \\ ${ }^{4}$ Laboratory of Molecular Adaptation, Department of Molecular Evolution, Centro de \\ Astrobiología, Consejo Superior de Investigaciones Científicas - Instituto Nacional de Técnica \\ Aeroespacial, Madrid, Spain. \\ ${ }^{5}$ Department of Plant and Environmental Sciences, The Institute of Life Sciences, The Hebrew \\ University of Jerusalem, Edmond J. Safra Campus, Jerusalem 9190401, Israel. \\ ${ }^{6}$ Department of Molecular Ecology, Max-Planck-Institut für Marine Mikrobiologie, Bremen, D- \\ 28359, Germany.
}

\section{Corresponding author:}

Tomeu Viver

Marine Microbiology Group

Department of Animal and Microbial Biodiversity

Mediterranean Institute for Advanced Studies (IMEDEA, CSIC-UIB)

E-07190, Esporles

Spain

Tel: +34 971611827

Email: tviver@imedea.uib-csic.es

Key Words: metagenomes, hypersaline environments, temporal series, determinism, resilience

This article has been accepted for publication and undergone full peer review but has not been through the copyediting, typesetting, pagination and proofreading process which may lead to differences between this version and the Version of Record. Please cite this article as doi: $10.1111 / 1462-2920.14790$ 


\section{Abstract}

While the dynamics of microbial community assembly driven by environmental perturbations have been extensively studied, our understanding is far from complete, particularly for lightinduced perturbations. Extremely halophilic communities thriving in coastal solar salterns are mainly influenced by two environmental factors - salt concentrations and high sunlight irradiation. By experimentally manipulating light intensity through the application of shading, we showed that light acts as a deterministic factor that ultimately drives the establishment of recurrent microbial communities under near-saturation salt concentrations. In particular, the stable and highly change-resistant communities that established under high-light intensities were dominated ( $>90 \%$ of metagenomic reads) by Haloquadratum spp. and Salinibacter spp. On the other hand, under 37-fold lower light intensity, different, less stable and change-resistant communities were established, mainly dominated by yet unclassified haloarchaea and relatively diverse photosynthetic microorganisms. These communities harboured, in general, much lower carotenoid pigment content than their high-irradiation counterparts. Both assemblage types appeared to be highly resilient, re-establishing when favourable conditions returned after perturbation (i.e., high-irradiation for the former communities and low-irradiation for the latter ones). Overall, our results revealed that stochastic processes were of limited significance to explain these patterns.

\section{Introduction}

The ecosystem-specific assemblages of microbial communities are the consequence of complex biotic and abiotic interactions with the physico-chemical and biological environment (Chesson, 2000). Amongst abiotic forces, salinity has been described as a major driver determining microbial community composition in a wide range of environments (Lozupone and Knight, 2007). Solar salterns, in particular, are human-controlled semi-artificial environments used for the harvesting of salt for human consumption. These environments are operated in repeated cycles of increasing salt concentration, precipitation and feeding with natural saltwater. Several studies have shown that salterns harbour recurrent microbial communities each year (Casamayor et al., 2002; Gomariz et al., 2014). The communities usually show low diversity, generally consisting of two major lineages i.e. the archaeal Halobacteria and the bacterial halophilic family of Salinibacteraceae, order Rhodothermia (Gomariz et al., 2014; Mora-Ruiz et al., 2018), but with relatively high species and genus diversity within each lineage. To cope with these extreme conditions of salt concentrations close to or above $\mathrm{NaCl}$ saturation $(\sim 36 \%)$ and direct sun irradiation, halophilic microorganisms have evolved osmotic survival strategies, such as osmoprotectants and compatible solutes, and also distinct DNA repair systems and photolyases to cope with UV radiation stresses (Kurth et al., 2017). Besides salinity, irradiation is probably the second most relevant environmental driver in such systems. 
Cyclic successions of microbial communities are hypothesized to be driven by deterministic processes (Chafee et al., 2018), and the understanding of the mechanisms controlling microbial successions is currently an important open question in ecology (Zhou et al., 2014). It is thought that deterministic and stochastic processes occur simultaneously but their relative importance in structuring microbial communities is often unknown. Generally, if stochastic processes (i.e. random birth, death, colonization, extinction, and speciation) control microbial community assembly then high variation in species composition (beta-diversity) is expected between sites that experience similar environmental conditions (Zhou et al., 2014). In contrast, deterministic processes dominate when microbial communities differ between sites and these are tightly linked to differences in environmental conditions between the sites (i.e. salinity and irradiation differences). Saltern microbial communities generally show high similarities in high taxa (i.e., genera, families or higher; Casamayor et al., 2002; Gomariz et al., 2014). However, it is not clear whether the same communities, at the species and subspecies levels, re-establish after each cycle of brine filling, evaporation, and precipitation during the same or different seasons each year. Accordingly, it is not known to what extent deterministic processes drive the succession patterns in solar salterns and what microbial functions are selected for by the changing conditions in salt saturation and light intensity.

The use of mesocosm and microcosm experiments with pulsed abiotic disturbances (e.g., extreme temperature, salt and $\mathrm{pH}$ and toxic chemicals) can help reveal the degree to which different environmental factors may stochastically or deterministically act on microbial community dynamics and composition (Zhou et al., 2014). Based on how microbial populations and their communities respond to disturbances, they could be categorized as either (i) resistant to the perturbation, understood as the degree to which a community is insensitive to a disturbance, (ii) resilient, i.e., community structure changes but returns to original state when the environment conditions return to their original state, or (iii) not resilient, i.e., altered community structure and/or functional redundancy with respect to the original community (Allison and Martiny 2008). Exhaustive time-series before and after the application of environmental disturbances are important in order to quantify the level of resistance and resilience of microbial communities to disturbances and to elucidate the exact underlying responses and mechanisms.

In this study, we analysed the changes in the microbial communities thriving in the solar salterns of Es Trenc, located in the south of the Mallorca island (Spain), after continuous shading and sudden uncovering (i.e. a 37-fold reduction or increase in sun irradiation, respectively) in two non-consecutive years. Community dynamics were studied by means of metagenomics as well as enumeration of microbial cells and virus-like particles (VLP). The experiment allowed us to evaluate the relative importance of determinism vs. stochastic processes and the community resistance and resilience to major environmental disturbances that are highly relevant for solar salterns, i.e., light intensity and salinity concentration. 


\section{RESULTS}

\section{Experimental setup}

From a group of six adjacent ponds (Sup. Fig. S1), separated from each other by less than 1 meter, and each containing about $15 \mathrm{~m}^{3}$ of brine, three ponds (E1, E4 and E5) were selected in year 2012 for the mesocosm experiments investigated herein (Fig. 1; Sup. Fig. 1); the remaining three ponds (E2, E3 and E6) were used for other experiments not reported here. All ponds in this study belonged to a broader collection of newly constructed crystallizers for salt harvest and were fed with the same inlet brines as all the remaining ponds in the vicinity that have been used for decades as crystallizers. Ponds were initially filled and regularly refilled with brine including in the three months prior to the start of the experiment (Aug 2012), and then allowed to evaporate which increased the salinity from $17 \%$ in May to saturation or close to saturation levels (34\% to $38.4 \%$ ) by early August (Sup. Table S1), just before the onset of the experiment. Ponds E1 and E4 both experienced regular daily sun irradiation, but E5 was kept covered by a thick mesh in the same time interval, depleting the sun light intensity by about 37 fold for a period of the three months prior to sampling, though light was never completely depleted. Light was reduced from an intensity of $1880 \mu \mathrm{mol} \mathrm{s} \mathrm{s}^{-1} \mathrm{~m}^{-2}$ to $50 \mu \mathrm{mol} \mathrm{s} \mathrm{m}^{-1} \mathrm{~m}^{-2}$ (Sup. Table S1). We refer to E5 as the short-shaded-2012 pond. On the day of the sampling (T0, August 2012; after 3 months of shade operation), the short-shaded-2012 pond E5 was uncovered, and the pond E4, which was treated as the control up to that time point (no light depletion), was covered with the mesh (Fig. 1; Sup. Fig. 1). The microbial communities of the three ponds were subsequently followed for one-month with regular sampling and no brine refilling.

After our experiment in 2012, all three ponds were subjected to the regular refilling and continuous evaporation cycles for two years, from September 2012 to August 2014, following the normal activity of the salt-producing facility. The shaded pond (E4) was kept covered during this two-year period and we refer to it as long-shaded-2014. In August 2014, the long-shaded2014 pond E4 was uncovered, and a new, regularly-operated (uncovered) pond E6 was shaded with the mesh thereby switching the irradiation conditions between E4 and E6 ponds. The microbial communities of the three ponds E1, E4 and E6 were subsequently followed for onemonth with regular sampling at 1 day, 1 week, and 1 month, with no brine refilling. In the year 2014, and for the metagenome analyses, the zero timepoints of the ponds E1, E2, E5 and E6 (Fig. 1; Sup. Fig. 1) were considered controls as they had not been submitted to any pressure in the previous 23 months (i.e., they all underwent regular refilling and continuous evaporation cycles for two years). Additional details of the experimental procedures can be found in the Materials and Methods.

Spatial and temporal stability of prokaryotic community structure in control ponds (highirradiation communities) 
We conducted a first comparison amongst all samples that represented the control (no shading perturbation) such as those of the control E1 pond (no shading), and the initial sampling timepoints of E4 in 2012 and E2, E5 and E6 of 2014 (Fig. 1). In general, all ponds that were considered controls showed similar salinities (above saturation; 38.4\% $-40 \%$ ), neutral pH values $(7.4-7.5)$ and similar temperatures $\left(26.3^{\circ} \mathrm{C}-32.4^{\circ} \mathrm{C}\right.$ at time zero and $28.3^{\circ} \mathrm{C}-31.6^{\circ} \mathrm{C}$ after one month; Sup. Table S1) at the same timepoints. Total cell densities determined by DAPI staining were, on average, $3.27 \times 10^{7}$ and $4.88 \times 10^{7}$ cells $/ \mathrm{ml}$ in 2012 and 2014 , respectively (Fig. 2 and Sup. Table S2). The percentage of archaeal cells measured by CARDFISH ranged between $72.2 \%$ and $82.2 \%$, and bacterial cell counts were between $17.8 \%$ and $27.8 \%$ in 2012. In 2014, the percentage of Archaea ranged between $70.8 \%$ and $74.0 \%$, while Bacteria were between $26.0 \%$ and $29.2 \%$.

Operational Phylogenetic Unit (OPU) diversity. Analysis of 16S rRNA gene fragments retrieved from the trimmed metagenomic reads, showed those associated with the Halobacteria class to be the most abundant (Sup. Text ST1 and Sup. Fig. S2), with Haloquadratum $(9.2 \pm 1.0 \%$ in 2012 and $9.3 \pm 1.4 \%$ in 2014), Halobaculum $(8.2 \pm 1.8 \%$ in 2012 and $0.9 \pm 0.4 \%$ in 2014), Halorubrum (11.6 $\pm 3.1 \%$ in 2012 and $13.2 \pm 3.1 \%$ in 2014) and Halonotius $(8.05 \pm 0.9 \%$ in 2012 and $32.79 \pm 4.7 \%$ in 2014) as the most abundant representative genera. For the bacterial domain, the most abundant taxon corresponded to the genus Salinibacter $(17.3 \pm 5.9 \%$ of the total 16S rRNA gene fragments). OPU classification demonstrated that the taxonomic profiles of all control samples were not significantly different ( $p$-values $>0.3843$ using the KolmogorovSmirnov test) between samples of the same or different years (Sup. Table S3-A).

Metagenome assembled genomes (MAGs)diversity. The highest quality MAGs of the control ponds were recovered from the co-assembly of all 2014 samples that were sequenced at higher coverage compared to the 2012 control samples (see Sup. Texts ST2 and ST3). These MAGs were used to quantify abundance of the corresponding populations in all samples by read recruitment. Altogether, we were able to recover a total of 19 MAGs (Table 1). In agreement with the 16S rRNA gene-based data reported above, the most abundant MAGs in all the samples were identified as a member of the species Hqr. walsbyi (MAG C1), an as yet unclassified species of the genus Halorubrum (MAG C16), and two uncultured Salinibacter species (MAGs C2 and C20). Fourteen additional MAGs were also obtained, all being representatives of Halobacteria.

Accordingly, the temporal dynamics of these (control) communities during the one month period of sampling and, even between two non consecutive years, showed high stability in their taxonomic and functional gene composition, physicochemical characteristics and DAPI/FISH cell counts (Fig. 2 and 3, Sup. Fig. S3, Sup. Tables S1 and S3). In general, the most abundant populations (in both MAGs and OPUs; Fig. 4 and Sup. Fig. S2 respectively) persisted, and their relative abundances differed only slightly between the two sampling years. We designated these communities as high-irradiation adapted. 


\section{Taxonomic and functional shifts under shaded conditions (low-irradiation communities)}

The E5 short-shaded-2012 pond was under shade for 3 months and the E4 long-shaded-2014 pond was continuously shaded for two consecutive years (Fig. 1; shown with green colour). Evaporation rates in the covered ponds were always lower than in the controls, and their brines never showed salt precipitates covering the sediments $34 \%$ salt concentration for the shortshaded-2012 and 29\% for the long-shaded-2014 at maximum). The control brines were red/pink in colour; in contrast, the shaded brines were green/brown (Sup. Fig. S1).

OPU diversity. In both years, the shaded ponds showed higher OPU diversity and richness than the controls (Sup. Fig. S4a, b, insets; Sup. Table S4), and the differences were due to the bacterial, rather than the archaeal, components (see below). The higher diversity was also reflected by the OPU rarefaction curves, which did not saturate for the shaded ponds (Sup. Fig. S4). Unlike the control ponds, the OPU composition in the short-shaded-2012 and long-shaded2014 was significantly different ( $p$-value 2.93e-08, Kolmogorov-Smirnov test; Sup. Fig. S2; Sup. Table S3). However, we found that, in general, the same dominant populations were shared between the two shaded ponds in both years, albeit in distinct proportions (Sup. Fig. S2 and Sup. Spreadsheet T2). For instance, in both shaded ponds, the seven dominant bacterial OPUs were two uncultured members of the Spiribacter genus (OPU181 and OPU182) representing $\sim 10 \%$ in the short-shaded-2012, and $\sim 2 \%$ in the long-shaded-2014, Salinibacter (OPU396 and OPU397 3.5\% in both years), the Bacteroidetes member Fodinibius sp. (OPU400; 4\% in both years) and Psychroflexus sp. (OPU372; 2.33\% in short-shaded-2012, 0.5\% in long-shaded2014), the uncultured alphaproteobacterial Rhodobacteraceae (1.5\% in short-shaded-2012) and the cyanobacterial Euhalothece (OPU613; 1.31\% in short-shaded-2012, 0.1\% in long-shaded2014). The MASH-based distances and the taxonomic differences of the shaded ponds relative to the controls were also most pronounced among all comparisons performed (Fig. 3; Sup. Fig. S3 and Text ST4). In contrast to the bacterial fraction, the top 10 most abundant OPUs (making up $47 \%$ of the total abundance) of the archaeal fraction were the same between the shaded and the control ponds in both years (Sup. Fig. S2). The differences in archaeal composition when compared to the control ponds were limited to the relative proportions of the low abundant OPUs. For instance, the OPU714, associated with Natronomonas spp., was always more abundant under low-irradiation relative to ambient condition (control), and in both years. We considered these recurrent communities with shared major taxa to be low-irradiation adapted.

MAGs diversity. The best MAGs recovered from the shaded ponds were obtained by population genome binning of the co-assembly of the T0 samples, one and two days after uncovering the shade in 2012, resulting in 7 good quality MAGs (e.g. completeness $>70 \%$ and contamination $<10 \%$; Table 1; Konstantinidis et al., 2017). The MAG S41 was the most abundant in both years and was identified as a yet uncultured, new species of the family Halorubraceae (see Sup. Text ST5). The next most abundant MAGs were, MAG S42 almost identical to MAG C1 from the control pond with $99.94 \%$ ANI and identified as Hqr. walsbyi, MAG S44 almost identical to MAG 
C16 from the control pond with 99.57\% ANI and identified as an uncultured species of the genus Halorubrum (Sup. Table S5), and MAG S46 identified as Spiribacter sp. (Table 1). We were not able to recover any Salinibacter MAGs from these samples, although a few reads with high identity to Salinibacter 16S rRNA genes were detected. The differences in the community structure between years observed at the OPU (e.g. 16S rRNA gene) level were more pronounced compared to the MAG level. This is presumably due to the lack of binning of low abundance organisms that were mainly responsible for the differences observed between the two years according to the OPU diversity. The high-irradiation and low-irradiation communities showed inverted abundances of the most representative taxa. The halobacterial MAGs C1, C3, C4, C5, C8, C11 and C14 and the Salinibacter MAG C2 were twice as abundant in the highirradiation assemblage, and reciprocally, MAGs S41, S46, S51, S52, and S53 showed higher abundance in the low-irradiation assemblage (Table 2). Interestingly, MAG C30, which originated from binning the control ponds, was also a major component of the low-irradiation communities, with its abundance values being double of those in the control ponds.

Diversity in photosynthetic microorganisms. Conspicuously, brines in the shaded pond were green/brown in colour, clearly different from the common red/pink of the control ponds (Sup. Fig. S1), which harboured Dunaliella sp. as the major photosynthetic eukaryote (Sup. Text ST6, Fig. S5A, and Tables S6 and S7). The combination of optical microscopy, metagenomic analysis, 18S rRNA gene amplicon sequencing and pigment determination (Sup. Text ST6) suggested that the shaded brines exhibited a similar abundance of Dunaliella sp. as the controls, but with an additional larger diversity of photosynthetic organisms. We observed a conspicuous predominance of large $(20 \mu \mathrm{m})$, rod-shaped autofluorescent organisms (Sup. Fig. $\mathrm{S} 5 \mathrm{C}$ ) that could be related to some type of red algae (Rhodophyceae). The pigment analyses (Sup. Text ST6 and Fig. S6) indicated that the differences in colour were mainly due to a lower concentration of Dunaliella-derived $\beta$-carotene and the higher chlorophyll content of the community under light-depleted conditions.

\section{Taxonomic and functional shifts of low-irradiation communities after removing shade}

Once uncovered and exposed to ambient irradiation (from $50 \mu \mathrm{mol} \mathrm{s}^{-1} \mathrm{~m}^{-2}$ to $1880 \mu \mathrm{mol} \mathrm{s}^{-1} \mathrm{~m}^{-2}$ ), the microbial community structure of the two (previously) shaded ponds changed rapidly and resembled closely the communities in the control ponds after one month (Fig. 3). The shifts were very similar in both ponds despite the fact that they were shaded for different durations or years. In both ponds, salinity increased from below saturation (34\% for the short-shaded-2012 and $29 \%$ for the long-shaded-2014) to saturation (36\% to $38.4 \%$ respectively). The environmental transition promoted changes in the most abundant OPUs (Sup. Fig. S2) and MAGs that were consistent with our categorization as high- (after shade was removed and salinity increased) and low-irradiation (before the removal of the shade, and just below $\mathrm{NaCl}$ saturation) communities. In accordance with these findings, the Bray-Curtis and MASH distance values between the short-shaded-2012 and long-shaded-2014 and the control ponds clearly 
decreased over time (i.e., the corresponding communities became more similar in composition), whereas the values amongst the control samples remained stable (Fig. 5).

The low-irradiation communities transitioned to a structure that was similar to that of the control just after one month of exposure to a high-irradiation. Interestingly, community diversity, measured by metagenomic read-redundancy values (i.e., Nonpareil curves) and Chao- 1 indices (OPU-based) showed a pulsed increase in diversity immediately after removing the shade (Sup. Fig. S4 and Sup. Table S4) and returned to similar values to those of the control ponds after about one week. Specifically, the fast and sharp peak of increase in diversity was largely attributable to an increase in the number of bacterial OPUs (Sup. Table S4). The changes in the community structure during this transition time of the first couple days after removing the shade were also evident in the cell abundances. DAPI and CARD-FISH counts revealed a sharp decline after just 1 day of high-irradiation exposure, mainly due to the decline of the archaeal populations (Fig. 2), and the cell counts quickly recovered after that period. This archaeal cell decline (cell lysis) was at least partly responsible for the transient peaks in richness and diversity of mainly bacterial, and presumably heterotrophic, species (Sup. Fig. S4 insets, and Sup. Table S4). In addition, the initial sharp decrease in archaeal cells was followed with a sharp 2.5-fold increase of virus-like particles (VLP) after $\sim 3$ days of sunlight exposure (only measured in the long-shaded-2014; Sup. Fig. S7, Table S8 and Text ST7).

In the long term, i.e., 1 month after removal of the shade, and mirroring the beta-diversity trends, the community cell densities in both short-shaded-2012 and long-shaded-2014 ponds tended to stabilise, with slightly lower values than the initial sampling point (T0), and with similar bacterial/archaeal proportions to the control ponds. Mirroring the OPU observations, we observed a specific decrease in the abundances of MAGs enriched or recovered from the lowirradiation communities in parallel with an increase in the abundances of MAGs enriched or recovered from high-irradiation communities to form a final taxonomic structure similar to the control pond after one month (Table 2). For example, the most abundant archaeal and bacterial MAGs under shaded conditions, i.e., Halorubrum sp. (MAG S41) and Spiribacter sp. (MAG S46), experienced a gradual decline over time after shade was removed (Fig. 4B). Conversely, Hqr. walsbyi (MAG S42) and Salinibacter sp. (MAG C2) ended up being by far the most abundant populations after one month. Hence, multiple lines of evidence, e.g., cell counts, OPU diversity and MAG relative abundance, consistently showed similar resilience trends after perturbation i.e., removal of the shade, albeit with different resolution.

Finally, and consistently with the higher diversity indices, we observed that in both shortshaded-2012 and long-shaded-2014 (before removal of the shade) there was generally higher functional diversity than in the control ponds (Sup. Fig. S8). Control and shaded ponds after removal of the shade exhibited a continuous decrease in their Bray-Curtis dissimilarity values over the sampling time for both taxonomic and functional diversity, reflecting the rapid convergence of both microbial communities towards a high-light-adapted state typical of unperturbed crystallizer ponds (Sup. Fig. S8). 


\section{Dynamics of the high-irradiation communities after light depletion}

We also performed the reverse experiment with two ponds, i.e., apply the same shading mesh after the ponds had stabilized to ambient light, in order to test for differences and similarities in the response of the microbial communities relative to those in the removal of shade treatment. For this, pond E4 in 2012, which debuted in salt harvest at TO and had an identical pretreatment as the E1 control pond, and pond E6 in 2014, which had all been subjected to the regular evaporation and refilling procedure during the two years prior to the treatment (i.e., application of shade), were used. Both the E4 pond in 2012 and the E6 pond in 2014 were covered with the mesh just after taking the T0 sample, depleting the sun irradiation by about 37 fold.

On the basis of OPUs and metagenome MASH distances (Sup. Fig. S3 and Fig.. 3 respectively), we did not observe significant changes in the high-irradiation community structures at the short (1-2 days) and medium (1 week) time points after shading. The major taxa of the communities were similar in the two sampling years and also exhibited similar dynamics as shown by their OPU diversity (Sup. Tables S4 and S9 and Spreadsheet Tables T7 and T8) and MAG composition (Sup. Fig. S9). However, shortly after the treatment was applied ( 1 day), the community experienced a sharp peak followed by a gradual decline in cell abundances that subsequently recovered, which was reminiscent of the one observed with the treatment of removing the shade (Fig. 2, pond E4). The reduction in cell counts coincided with increased diversity (Sup. Table S4) and a corresponding 3-fold increase in VLP (Virus Like Particles) counts (Sup. Fig. S7). The stable taxonomic and functional diversity, and the stable viral dynamics during the one-month sampling period indicated a relatively low effect of irradiation intensity reduction, at least for this period. However, and despite the apparent stability, shading of pond E4 in 2012 did cause some observable minor changes to the community structure, and the prolonged shading for two years led to a distinct structure that we named long-shaded-2014. Altogether, the changes after shading were slower compared to those previously observed after removing shade from the ponds.

\section{Functional gene shifts during community transition.}

Functional gene annotation analysis using the SEED subsystems reflected the distinct tempo in microbial community response we observed between the two treatments, i.e. the fast low-tohigh- and the slow high-to-low change in irradiation (Sup. Texts ST4 and ST10, and Fig. S10 and S11). In general, the high-irradiation communities showed a higher occurrence of genes related to DNA protection and repair. On the other hand, the low-irradiation communities exhibited a high number of genes related to photosynthesis, autotrophy and dimethylsulfide (DMS) and dimethylsulfoniopropionate (DMSP) metabolism (best matching to some archaeal members of Haloplanus, Halobellus or Haloarcula; and Spiribacter bacteria), as well as a 
relatively high abundance of D-ribose utilisation and compatible solute synthesis genes. Moreover, the abundance of genes related to autotrophy $\left(\mathrm{CO}_{2}\right.$ uptake and carboxysome formation) was increased in the shaded conditions, and were mostly assigned to cyanobacteria (Geitlerinema with a $95 \%$ identity).

Notably, removing the shade treatment promoted shifts in functional gene content that were already apparent in the short and medium sampling time points, and nearly undetectable at the OPU and genome levels. These shifts included -for example- an increase in DNA-binding proteins (DNA repair bacterial DinG and relatives, DNA repair bacterial RecBCD pathway, DNA repair bacterial photolyases), photolyases, and genes related to the shikimate pathway just after one week of ambient sunlight exposure (Sup. Fig. S10). An increase in the abundance of genes related to cobalamin and genes involved in the UvrABC system (genes related to DNA repair) was also observed.

Conversely, only minor gene content shifts were observed in the slow transition from high- to low-irradiation communities relative to the control ponds (Sup. Fig. S11). For example, and in line with the increased photosynthetic diversity under low-light conditions, we observed a significant higher number of genes involved in the release, mineralisation, and catabolism of dimethyl sulfide (DMS) and dimethylsulfoniopropionate (DMSP).

\section{Resilience and deterministic processes driving community dynamics}

All $\beta$-diversity analysis based on (i) MAG dynamics using the Bray-Curtis metric, (ii) MASH distances of all metagenomic reads and (iii) Bray-Curtis using OPU diversity, showed a strong increase in similarity between both short-shaded-2012 and long-shaded-2014 communities and their controls after uncovering the ponds (Fig. 5 and Supplementary Figure S12). On the other hand, the reverse experimental manipulation (i.e., shading the ambient irradiation ponds) revealed less dramatic shifts during the one-month-long sampling period with a relatively slow transition that was indicative of a strong resistance to change.

A null model analysis (Zhou et al., 2014; Chase et al., 2011; for further details see Sup. Material and Methods) was carried out on datasets from each of the two years considering each condition and each time (i.e., 0 hours, 1 day, 2 days, 1 week and 1 month) independently. To quantify the importance of deterministic processes in light treatments (Fig. 6), the similarity for each pairwise comparison and the null expected similarity divided by the observed similarity was presented in Figure 6. This ratio is designated as selection strength (SS) and provides an estimate of the deterministic selection processes (Zhou et al., 2014). Deterministic processes (opposed to stochastic) are expected to drive the microbial assembly when the deterministic selection is $>50 \%$. In the controls, the deterministic processes explained between $92 \%$ and $97 \%$ of the variation observed over time (Fig. 6, blue line). Similarly, but with even stronger influence after shading the ponds, community dynamics seemed to be solely driven by deterministic processes (effects ranging from $97 \%$ to $100 \%$, yellow line). In contrast, while the deterministic 
processes contributed around $98 \%$ in the initial transition stage after previously covered ponds were exposed to high light intensity, this value decreased to a minimum of $84 \%$ after one week (Fig. 6, red line). The slightly higher effect of stochastic processes during the transition phase of this light exposure treatment was probably promoted by the combination of light and salinity increase, in contrast to the other two cases in which only light was acting as a driving factor.

\section{DISCUSSION}

Light and salt act as deterministic processes driving community dynamics.

Salterns undergo seasonal (Gomariz et al., 2014) and even daily (Andrade et al., 2015) fluctuations in environmental conditions such as temperature, irradiation or ionic composition. In order to reduce the influence of such fluctuations in our analyses, we performed the experiments at the same time of the day and in the same season in two non-consecutive years. It was remarkable that despite the slightly different initial states, microbial communities from the same treatment or control ponds were nearly identical in their structures based on the species and gene composition. In all cases, the basic composition determined by OPUs and MAGs was reminiscent of the previous reports on the crystallizers of Mediterranean solar salterns (Antón et al., 2000; Gomariz et al., 2014; Pašić et al., 2005; Mora-Ruiz et al., 2018). In addition, brines exhibited the typical red-pigmentation originating by the combination of the presence of the Dunaliella sp. algae with various carotenoid-encoding halophilic prokaryotes as previously reported (Oren and Rodríguez-Valera, 2001; Oren 2005). These findings suggested that such high-irradiation communities are well adapted to extreme salinity and irradiation, a fact that is supported by our observed relative high abundance of genes related to DNA protection and repair. These findings were also consistent with those reported for high altitude hypersaline lake with strong light incidence (Kurth et al., 2017). Results from communities thriving under very low irradiation conditions exhibited slight differences. These results, consistent with distinct initial states, showed significant, albeit relatively small differences in the composition of the low abundant taxa, and on the relative abundances on the highly represented taxa, mainly composed of yet unclassified organisms. To our knowledge, this is the first report of the community composition of hypersaline brines under aerobic and very low irradiation intensity.

The most abundant MAG in both high and low-irradiation adapted communities was a member of the archaeal Hqr. walsbyi (99.8\% ANI with the reference genome (Bolhuis et al., 2006)), and this finding probably underlies the generalist nature of this organism, which has been considered a microbial weed (Craig et al., 2013). In the light-depleted hypersaline communities, Salinibacter was not the most dominant bacterium (as is frequently observed salterns; Antón et al., 2000; Mutlu et al., 2008; Gomariz et al., 2014; Mora-Ruiz et al., 2018), but was accompanied by several other members of the bacterial domain, especially Spiribacter sp. Spiribacter sp. has been reported as moderately to extremely halophilic, thriving in brines from 10\% concentration up to around 34\% (León et al., 2014; León et al., 2017). Therefore, the salt concentrations below saturation of the covered brines were presumably responsible, at least in 
part, for the overall composition of taxa observed. It was remarkable that after uncovering the shaded ponds the brines were green-brown, with a higher diversity of photosynthetic microorganisms in accordance with low-light fostering higher photosynthetic diversity (Majchrowski and Ostrowska, 2000). However, the most abundant taxa in the shaded brines were compatible with being capable of synthetizing carotenoids that give the typical red colour pigmentation of the ponds (Oren and Rodríguez-Valera, 2001; Oren 2005) and act as irradiation-protectants (Demming-Adams and Adams, 2002). Therefore,the synthesis of these carotenoids seems to be downregulated under the shaded condition in a physiological adaptation and this accounted for the colour of the ponds observed.

The dynamics differed qualitatively between the high- and low-irradiation-adapted communities. The latter experienced relatively fast changes upon removal of the shade within one month, promoting a clear transition towards the high-irradiation structure just after one month, which was dominated by Hqr. walsbyi and Salinibacter sp. similar to the untreated salterns (Antón et al., 2000; Antón et al., 2008). In contrast, the high-irradiation communities, after being covered, transitioned to a low-irradiation structure over longer time scales (i.e., longer than one month). This more resistant nature of the high-irradiation taxa and their communities was most probably due to the long-term adaptation of the corresponding taxa to the conditions in the saltern systems, e.g., the treatments applied (light intensity and salt concentration) were highly relevant for the salterns. The adaptation was likely supported by the high abundance of suitable substrates that could maintain the community structure for a prolonged period independent of the degree of light depletion and the stable salt concentration (saturation) during the sampling period.

Overall, community transition after treatment was highly influenced by deterministic processes, which explained between $92 \%$ and $100 \%$ of the diversity changes during the one month of sampling. Only in the shaded mesocosms right after exposure to light, an isolated, relatively small increase in stochasticity in the short-term (max $14 \%$ at one week) observed, coinciding with a peak in taxa diversity. Alternatively, the transient increase in diversity could also be due to sampling both dying (e.g., low-light adapted taxa) and growing (e.g, high-light adapted) taxa, and not necessarily that a larger number of taxa grew. It is important to note that our sampling methodology did not discriminate between live vs. dead cells or even relic DNA. Altogether, it was clear that light intensity (and salt concentration of the low-irradiation ponds) acted as predominantly as deterministic processes in driving microbial diversity in hypersaline environments. Our observations were further reinforced by the fact that the experiments started at slightly different stages in the two years, (e.g., shading for 3 months vs. 2 years that most likely were responsible for the minor differences in the initial microbial community composition observed); yet very similar patterns were observed between the two years.

Transient peak of taxonomic diversity after light treatment 
As a short-term response, both light treatments coincided especially with a decline of the archaeal components in parallel with an increase of the virus-like particle (VLP) counts and bacterial diversity, consistent with previously reported over-expression of archaeal viruses after UV stress (Santos et al., 2011). Apparently, the increased light intensity affected the major groups through the effects of photoinhibition, changes in the photosynthetic populations, and viral stimulation effects. Probably the selective decline of (mainly) Archaea due to virus lysis (or predation) enabled the detection of bacterial taxa that were below the detection thresholds, i.e., members of the rare biosphere (Pedrós-Alió, 2006) that could even take advantage of the dissolved products after cell lysis to grow. However, as mentioned above, we cannot rule out that we sample both dying and growing cells. The reduction of the competitively dominant communities (Salinibacter spp. and Haloquadratum spp.) resulted in an increase in species richness, also consistent with the intermediate disturbance hypothesis, in which the highest diversity levels occur at the intermediate stages/timeframe after the disturbances (Zhou et al., 2014; Miller et al., 2011). Accordingly, only specialist species are favoured in a given environment in the absence of disturbances, and an intermediate disturbance is a factor maintaining the highest levels of diversity.

\section{Functional gene shifts after light treatment}

The distinct succession of the corresponding microbial communities after shading or removal of the shade treatment were also reflected by functional gene shifts. The low-irradiation community, when exposed to high light, rapidly showed gene shifts that were reflective of the community changes due to environmental stress. We especially detected an increase in abundance of genes related to osmotic stress, which tend to be accompanied by reactions related to oxidative stress in bacterial cells (Botsford and Lewis, 1990; Bojanovič et al., 2017). Genes related to the biosynthesis of compounds such as glutathione that can hamper oxidative damage under osmotic stress (Smirnova and Oktyabrsky, 2005), and ergothioneine, an amino acid with antioxidant and cytoprotective capabilities against cellular stressors (Cheah et al., 2012), were also detected in increased abundances. Further, we observed an increase in genes related to cobalamin, which can contribute to the reduction of the intracellular levels of ROSs (reactive oxygen species and oxidative stress) and the damage of biomolecules, enhancing cell survival when exposed to oxidative stress (Ferrer et al., 2016). Finally, the sudden light exposure (shade removal) promoted a rapid increase in genes involved in the UvrABC system (genes related to DNA repair).

On the other hand, despite the slower transition, after one month of light depletion we observed several significant, albeit rather small, changes such as increased subsystems related to Nudix proteins (nucleoside triphosphate hydrolases) that contribute to the intracellular removal of oxidised mutagenic, and therefore damaged nucleotides (Fisher et al., 2004), and DNA repair base excision genes. Interestingly, we also detected a significant increase in genes involved in the release, mineralisation, and catabolism of DMS and DMSP compounds produced by 
phytoplankton and seaweeds (Yoch, 2002), in line with the increased occurrence of photosynthetic organisms in the light-depleted ponds. We believe that the one-month samples showed the beginning of a transition of a high-irradiation community towards low-irradiation. However, additional samples were not available to more precisely estimate the time it takes to complete the transition.

Es Trenc solar salterns have been in use for centuries (www.salinasdestrenc.com) and therefore, the high-irradiation populations (mainly Haloquadratum spp. and Salinibacter spp.) may be well adapted to the system by the recurrent (human-driven) cycles of evaporation and refilling. Our results suggested that these communities are highly resistant to environmental changes (transition to low light intensity, for example) and resilient to pulsed environmental pressures. However, a substantial, prolonged reduction in light intensity caused the establishment of a different, more diverse community that was adapted to low-irradiation. Salt concentration and light intensity seem to be responsible for the establishment of recurrent communities on a cyclic basis, whereas high levels of irradiation appear to represent a stronger selection factor than shade.

\section{Experimental procedures:}

\section{Experimental site and sampling}

This study was carried out in the Mediterranean solar salterns at "Es Trenc", located on the south-east coast of the island of Mallorca (39 20' N; $2^{\circ}$ 59' E) in August 2012 and 2014. For further details, see the Experimental Setup in the Results section. All ponds were sampled at time zero (TO) just before the application of the treatment, and then regularly sampled during a one-month period for physicochemical parameters and cell and VLP counts. Samples for metagenomics were taken at time zero (T0), one day, two days, one week and one month after starting the experiment in both non-consecutive years. Ponds were not refilled until the experiment finished in each respective year. To control the light intensity, we used a plastic mesh (typically used for domestic sunshades; Sup. Fig. S1), which decreased the environmental light intensity from $1880 \mu \mathrm{mol} \mathrm{s}^{-1} \mathrm{~m}^{-2}$ to $50 \mu \mathrm{mol} \mathrm{s}{ }^{-1} \mathrm{~m}^{-2}$. The screen was removed or placed on the pond just after taking the time zero samples (initial sample T0 hours).

\section{Summary of the methods given in the supplementary material}

DNA extraction was performed as detailed in (Urdiain et al., 2008). The samples from the 2012 and 2014 experiments were sequenced using Illumina HiSeq and MiSeq, respectively, and trimming, assembly and gene annotation procedures are detailed in Supplementary Text ST1. Statistics of the metagenomic datasets obtained are provided in Sup. Text ST2. Metagenomic coverage, i.e., what fraction of the extracted DNA was sequenced, was predicted using Nonpareil v2.4 software (Rodriguez-R and Konstantinidis, 2014). MASH distance analyses (Ondov et al., 2016) were visualised in an NMDS plot using the vegan library (Oksanen et al., 
2007) in RStudio v3.2.2. For phylogenetic reconstruction purposes, 16S rRNA gene-encoding reads extracted from metagenomes and 18S rRNA gene amplicons were separately clustered at $98.7 \%$ nucleotide identity using QIIME. The representative sequences from each OTU (Operational Taxonomic Units) were aligned using SINA (Pruesse et al., 2007) and added to the reference database SILVA REF123 by the parsimony method implemented in ARB (Ludwig et al., 2004). The OTUs were clustered into OPUs (Operational Phylogenetic Units) as recommended by Mora-Ruiz (Mora-Ruiz et al., 2015). Rarefaction curves and statistical indices were calculated using the PAST statistical tool (Hammer et al., 2001), and divergence between samples was estimated based on phylogenetic distances between corresponding OPUs using non-parametric Kolmogorov-Smirnov tests (Jarek 2015).

Contigs with length over 1,000 bp were binned using MaxBin v2.1.1 (Wu et al., 2014) with default parameters. AAI (Average Amino-acid Identity) calculations of each MAG against the NCBI genome database were done using the Microbial Genomes Atlas (MiGA; Rodriguez-R et al., 2018). The abundance of the MAGs in each metagenome was calculated by mapping the reads using BLASTn (Altschul et al., 1990) and selecting reads with $\geq 98 \%$ similarity and alignment length $\geq 70 \%$. The number of mapped reads was divided by the total number of reads in each metagenome to provide the relative abundance of the MAG (\%) or divided by the size (bp) of the total length of the MAG to provide the X coverage value. The "Null Model Analysis" proposed by Chase et. al., (2011) was used to provide a quantitative estimate of the role of deterministic vs. stochastic processes in community composition based on MAG diversity. For this purpose, and following the methods used by Chase et al. (2011), we used the Jaccard index together with Bray-Curtis as they are the least vulnerable to errors of taxonomy, enumeration or geography, and give very similar error rates as reported by (Schroeder et al., 2018). Pigments were analysed using a HITACHI U-2900 spectrophotometer and viral count by flow cytometry (FACS Canto II cytometer). Microbial cell counts were carried out using DAPI, FISH and CARD-FISH methodology. All samples were immediately fixed with formaldehyde and processed for the fluorescence microscope counts as previously reported (Viver et al., 2017). Additional details on the experiments' methods are described in Supplementary Materials and Methods.

Raw metagenomic datasets are deposited in the European Nucleotide archive under study number PRJEB27445

\section{Acknowledgements}

The authors would like to thank Vladimir Benes and Arantxa López for metagenomes sequencing. The authors would particularly like to thank the whole team at Salines d'esTrenc and Flor de Sal SL for allowing the access to their facilities and their support in performing the experiments. This study was funded by the Spanish Ministry of Economy projects CGL201239627-C03-03 CLG2015_66686-C3-1-P and PGC2018-096956-B-C41 (to RRM), CGL2015_66686-C3-3-P (to JA) and CGL2015_66686-C3-2-P (to JEGP) which were also 
supported with European Regional Development Fund (FEDER) funds. RA was funded by the Max Planck Society. KTK's research was supported, in part, by the U.S. National Science Foundation (Award No. 1831582). TVP received a pre-doctoral fellowship (Nr. BES-2013064420) from the Spanish Government Ministry for Finance and Competition. RRM acknowledges the financial support of the sabbatical stay at Georgia Tech supported by the grant PRX18/00048 of the Ministry of Sciences, Innovation and Universities.

\section{Conflicts of Interest}

The authors declare there are no conflicts of interest

\section{References}

1. Allison, S.D., and Martiny, J.B.H. (2008) Resistance, resilience, and redundancy in microbial communities. Proc Natl Acad Sc USA 105: 11512-11519.

2. Altschul, S.F., Gish, W., Miller, W., Myers, E.W., and Lipman, D.J. (1990) Basic Local Alignment Search Tool. J Mol Biol 215: 403-410.

3. Andrade, K., Logemann, J., Heidelberg, K.B., Emerson, J.B., Comolli, L.R., Hug, L.A., et al. (2015) Metagenomic and lipid analyses reveal a diel cycle in a hypersaline microbial ecosystem. ISME J 9: 2697-2711.

4. Antón, J., Rosselló-Móra, R., Rodriguez-Valera, F., and Amann, R. (2000) Extremely halophilic bacteria in crystallizer ponds from solar salterns. Appl Environ Microbiol 66: 3052-3057.

5. Antón, J., Peña, A., Santos, F., Martínez-García, M., Schmitt-Kopplin, P., and RossellóMóra, R. (2008) Distribution, abundance and diversity of the extremely halophilic bacterium Salinibacter ruber. Saline Systems 4:15.

6. Begon, M., Townsend, C.R., and Harper, J.L. (2005) Ecology: From Individuals to Ecosystems. Fourth edition. Blackwell Publishing Ltd.

7. Bibby, T.S., Mary, I., Nield, J., Partensky, F., and Barber, J. (2003) Low-light-adapted Prochlorococcus species possess specific antennae for each photosystem. Nature $\mathbf{4 2 4}$ : 1051-1054. 
8. Biller, S.J., Berube, P.M., Lindell, D., and Chisholm, S.W. (2015) Prochlorococcus: the structure and function of collective diversity. Nature 13: 13-27.

9. Bolhuis, H., Palm, P., Wende, A., Falb, M., Rampp, M., Rodriguez-Valera, F. et al. (2006). The genome of the square archaeon Haloquadratum walsbyi: life at the limits of water activity. BMC genomics 7: 169 .

10. Casamayor, E.O., Massana, R., Benlloch, S., Ovreas, L., Díez, B., Goddard, V.J., et al. (2002) Changes in archaeal, bacterial and eukaryal assemblages along a salinity gradient by comparison of genetic fingerprinting methods in a multipond solar saltern. Env Microbiol 4: 338-48.

11. Chafee, M., Fernàndez-Guerra, A., Buttigieg, P.L., Gerdts, G., Murat, A., Teeling, H., et al. (2018) Recurrent patterns of microdiversity in a temperate coastal marine environment. ISME J 12: 237-252.

12. Chase, J.M., Kraft, N.J.B., Smith, K.G., Vellend, M., and Inouye, B.D. (2011) Using null models to disentangle variation in community dissimilarity from variation in a-diversity. Ecosphere 2: art24.

13. Chesson, P. (2000) Mechanisms of maintenance of species diversity. Annu Rev Ecol Syst 31: 343.

14. Cray, J.A., Bell, A.N., Bhaganna, P., Mswaka, A.Y., Timson, D. J., and Hallsworth, J. E. (2013). The biology of habitat dominance; can microbes behave as weeds? Microbial biotech 6: 453-492.

15. Demming-Adams, B., and Adams, W.W. (2002) Antioxidants in photosynthesis and human nutrition. Science 298: 2149-2153.

16. Gomariz, M., Martínez-García, M., Santos, F., Rodriguez, F., Capella-Gutiérrez, S., Gabaldón, T., et al. (2014) From community approaches to single-cell genomics: the Discovery of ubiquitous hyperhalophilic Bacteroidetes generalists. ISME J 9: 1-16.

17. Hammer, O., Harper, D., and Ryan, P. (2001) PAST: paleontological statistics sortware package for education and data analysis. Paleontol Electron 4: 9.

18. Jarek, S. (2015) Package 'mvnormtest': Normality test for multivariate variables. 
19. Klähn, S., and Hagemann, M. (2011) Compatible solute biosynthesis in cyanobacteria. Env Microbiol 13: 551-562.

20. Konstantinidis, K.T., Rossello-Mora, R., Amann, R. (2017) Uncultivated microbes in need of their own taxonomy. ISMEJ 11: 2399-2406.

21. Kreyling, J., Jentsch, A., and Beierkuhnlein, D. (2011) Stochastic trajectories of succession initiated by extreme climatic events. Ecology Letters 14: 758-764.

22. Kurth, D., Amadio, A., Ordoñez, O.F., Albarracín, V.H., Gärtner, W., and Farías, M.E. (2017) Arsenic metabolism in high altitude modern stromatolites revealed by metagenomics analysis. Scientific reports 7: 1024.

23. León, M.J., Aldeguer-Riquelme, B., Antón, J., Sánchez-Porro, C., and Ventosa, A. (2017) Spiribacter aquaticus sp. nov., a novel member of the genus Spiribacter isolated from a saltern. Int J Syst Evol Microbiol 67: 2947-2952.

24. León, M.J., Fernández, A.B., Ghai, R., Sánchez-Porro, C., Rodriguez-Valera, F., and Ventosa, A. (2014) From metagenomics to pure culture: isolation and characterization of the moderately halophilic bacterium Spiribacter salinus gen. nov., sp. nov. Appl Environ Microbiol 80: 3850-7.

25. Lozupone, C.A., and Knight, R. (2007) Global patterns in bacterial diversity. Proc Natl Acad Sc USA 104: 11436-11440.

26. Ludwig, W., Strunk, O., Westram, R., Richter, L., Meier, H., Yadhukumar., Buchner A, et al. ARB; a software environment for sequence data. Nucleic Acids Res 2004; 32 : 1363-1371.

27. Majchrowski. R., and Ostrowska. M. (2000) Influence of photo- and chromatic acclimation on pigment composition in the sea. Oceanologia 42: 157-175.

28. Miller, A.D., Roxburgh, S.H., and Shea, K. (2011) How frequency and intensity shape diversity-disturbance relationships. Proc Natl Acad Sc USA 108: 5643-5648.

29. Mora-Ruiz, M.R., Font-Verdera, F., Díaz-Gil, C., Urdiain, M., Rodríguez-Valdecantos, G., González, G., et al. (2015) Moderate halophilic bacteria colonizing the phylloplane of halophytes of the subfamily Salicornioideae (Amaranthaceae). Syst Appl Microbiol 38: 406-416. 
30. Mora-Ruiz, M.R., Cifuentes, A., Font-Verdera, F., Pérez-Fernández, C., Farias, M.E., González, B., et al. (2018). Biogeographical patterns of bacterial and archaeal communities from distant hypersaline environments. Syst Appl Microbiol 41: 139-150.

31. Mutlu, M.B., Martínez-García, M., Santos, F., Peña, A., Guven, K., Antón, J. (2008) Prokaryotic diversity in Tuz lake, a hypersaline environment in inland Turkey. FEMS Microbiol Ecol. 65: 474-483.

32. Narasingarao, P., Podell, S., Ugalde, J.A., Brochier-Armanet, C., Emerson, J.B., Brocks, J.J., et al. (2012) De novo metagenomics assembly reveals abundant novel major lineage of Archaea in hypersaline microbial communities. ISME J 6: 81-93.

33. Oksanen, J., Kindt, R., Legendre, P., and O'Hara, B. (2007) Vegan: Community ecology package. Com ecol pack 10: 631-637.

34. Ondov, B.D., Treangen, T.J., Melsted, P., Mallonee, A.B., Bergman, N.H., Koren, S., et al. (2016). Mash: fast genome and metagenome distance estimation using MinHash. Genome biology 17: 132.

35. Oren, A., and Rodríguez-Valera, F. (2001) The contribution of halophilic Bacteria to the red coloration of saltern crystallizer ponds. FEMS Microbiol Ecol 36: 123-130.

36. Oren, A. (2005) A hundred years of Dunaliella research: 1905-2005. Saline Systems 4: $1-2$.

37. Overbeek R, Begley T, Butler RM, Choudhuri JV, Chuang HY, Cohoon M, et al. The subsystems approach to genome annotation and its use in the project to annotate 1000 genomes. Nucleic Acids Res 2005; 33: 5691-5702.

38. Partensky, F., Hess, W.R., and Vaulot, D. (1999) Prochlorococcus, a marine photosynthetic prokaryote of global significance. Microbiol Mol Biol Rev 63: 106-27.

39. Pašić, L., Bartual, S.G., Ulrih, N.P., Grabnar, M., and Velikonja, B.H. (2005) Diversity of halophilic archaea in the crystallizers of an Adriatic solar saltern. FEMS Microbiol Ecol 54: 491-498.

40. Pedrós-Alió, C. (2006) Marine microbial diversity: ca it be determined? Trends Microbiol 14: 257-263. 
41. Pruesse, E., Quast, C., Knittel, K., Fuchs, B.M., Ludwig, W., Peplies, J., et al. (2007) SILVA: a comprehensive online resource for quality checked and aligned ribosomal RNA sequence data compatible with ARB. Nucleic Acids Res 35: 7188-7196.

42. Rodriguez-Brito, B., Li, L., Wegley, L., Furlan, M., Angly, F., Breitbart, M., et al. (2010) Viral and microbial community dynamics in four aquatic environments. ISME $J$ 4: 739751.

43. Rodriguez-R, L.M., and Konstantinidis, K.T. (2014) Nonpareil: a redundancy-based approach to assess the level of coverage in metagenomics datasets. Bioinformatics $\mathbf{3 0}$ : 629-635.

44. Rodriguez-R, L.M., Gunturu, S., Harvey, W., Rosselló-Móra, R., Tiedje, J., Cole, J.R., et al. (2018) The Microbial Genomes Atlas (MiGA) webserver: taxonomic and gene diversity analysis of Archaea and Bacteria at the whole genome level. Nucleic Acids Res 46: W282-W288.

45. Santos, F., Moreno-Paz, M., Meseguer, I., López, C., Rosselló-Móra, F., Parro, V., et al. (2011) Metatranscriptomic analysis of extremely halophilic viral communities. ISME J 5: 1621-1633.

46. Schroeder, P. J., Jenkins, D.G. (2018) How robust are popular beta diversity indices to sampling error?. Ecosphere, 9: e02100.

47. Teeling, H., Fuchs, B.M., Becher, D., Klockow, C., Gardebrecht, A., Bennke, C.M., et al. (2012) Substrate-Controlled succession of marine bacterioplankton populations induced by a phytoplankton bloom. Science 336: 608-611.

48. Urdiain, M., López-López, A., Gonzalo, C., Busse, J., Langer, S., Kämpfer, P., et al. (2008) Reclassfication of Rhodobium marinum and Rhodobium pfennigii as Afifella marina gen. nov. comb. nov. and Afifella pfennigii comb. nov, a new genus of photoheterotrophic Alphaproteobacteria and emended descriptions of Rhodobium, Rhodobium orientis and Rhodobium gokarnense. Syst Appl Microbiol 31: 339-351.

49. Wegmann, K. (1986) Osmoregulation in eukaryotic algae. FEMS Microbiol Rev 39: 3743. 
50. Wu, Y.W., Tang, Y.H., Tringe, S.G., Simmons, B.A., and Singer, S.W. (2014) MaxBin: an automated binning method to recover individual genomes from metagenomes using an expectation-maximization algorithm. Microbiome 2: 26.

51. Zhou, J., Deng, Y., Zhang, P., Xue, K., Liang, Y., Van Nostrand, J.D., et al. (2014) Stochasticity, succession, and environmental perturbations in a fluidic ecosystem. Proc Natl Acad Sc USA 111: E836-E845. 


\section{TABLE LEGENDS:}

Table 1: Metrics for the high-irradiation (C) and low-irradiation (S) MAGs recovered from the control (E1, E2 and E5 samples year 2014) and short shaded metagenomas (year 2012) respectively. The ANI and AAI values are calculated against the closest reference genome. The metrics were calculated using the MiGA webserver (Rodriguez-R et al., 2018).

Table 2: $\log _{2}$-fold MAG abundance differences between high-irradiation $(C)$ and low-irradiation (S) MAGs recovered from the short-shaded (positive values) and control (negative values) metagenomes in both the 2012 and 2014 experiments. Positive 2-fold change values indicate a higher MAG abundance in the short and long shaded ponds (E5 year 2012 and E4 year 2014), and negative values indicate a higher abundance of the MAGs in control ponds. For MAGs showing similar abundances in both conditions (considered as Log2-fold change value <2), no value is given.

\section{FIGURE LEGENDS:}

Figure 1: Graphical representation of the experimental setup. All ponds (Sup. Fig. 1) were subjected to refilling - evaporation cycles since May of 2012 (i.e., for three months). E1, E2, E4 and E6 were permanently exposed to sunlight and E5 was shaded in May. E1 was the control pond, E4 (Hi-Shaded 2012) was a standard pond shaded at inception of the sampling at time zero in early August 2012, and E5 was the Short-Shaded pond uncovered at time zero. In year 2014 after 23 months of regular refilling - evaporation cycles, E1 was selected as control, E4 (the Long-Shaded 2014 pond) which had been covered since 2012 was uncovered and the cover was placed onto E6 (Hi-Shaded 2014) that was a control pond for 2012. Ponds E2 and E6 (in year 2012) and E2 and E5 (in year 2014; grey-shaded ponds) were only used as control at their respective time zero. Inserted values indicate the percentage of salts at the time sampled. Pink and green reflect the colour of the pond during the experiment. Shaded turned from deep green to pink after uncovering and letting evaporate, and vice-versa for the controls when shaded.

Figure 2: Cell counts over time as determined by fluorescence microscopy. Values are given as cells/ml (DAPI) and separately for Bacteria and Archaea in the different ponds.

Figure 3: Relatedness among of all metagenomes determined in this study. The graphs represent the Non-metric Multidimensional Scaling (NMDS) analysis of MASH-based distances that were calculated between all versus all metagenomic reads from year 2012 (A) and 2014 (B).

Figure 4: Shifts in abundances of the major populations over time based on MAGs. Graphs show the relative abundances of high-irradiation (C) and low-irradiation (S) MAGs recovered from panel $A$ the control and panel $B$ the shaded metagenomes in 2012 and 2014 experiments, respectively. 
Figure 5: Changes in microbial community similarity over time relative to the control (ambient light). Graphs show the MASH-based distances between the shaded - unshaded ponds and the control pond in 2012 (A) and 2014 (B). Bray-Curtis dissimilarity values based on abundance of MAGs (most abundant populations used only) in 2012 (C) and 2014 (D) for the same comparison. The reference control community used in all comparisons is the control E1 pond after 1 month of sampling.

Figure 6: The effect of deterministic processes over time. The $\mathrm{Y}$-axis show the relative contribution of deterministic vs stochastic processes in driving microbial community diversity patterns in samples from the two years (2012 and 2014) in different experiments (control ponds, long and short shaded after uncovering and both control after shading), during the one month sampling period. 
2012 1st filling in May $22^{\text {nd }}$ (inlet brines $17.2 \%$ ) \& weekly refill and evaporation cycles until August $8^{\text {th }} 2012$ (78 days) ponds were precipitating salt for the first time. E3 is not represented here as it is not relevant for the experiments

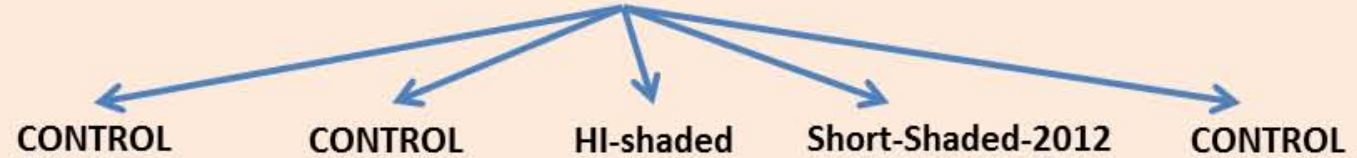

(E1)

(E2)

(E4)

(E5)

(E6)

TIME ZERO

(Aug 8)
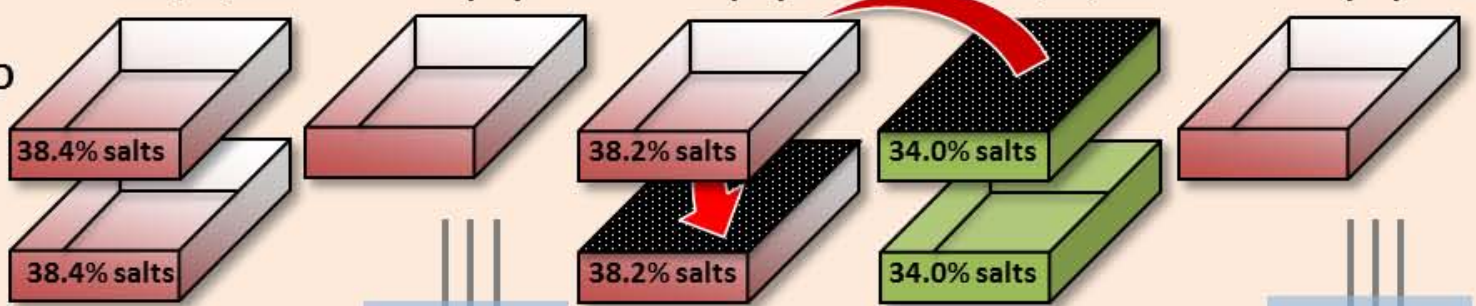

(1) Uyug 10)
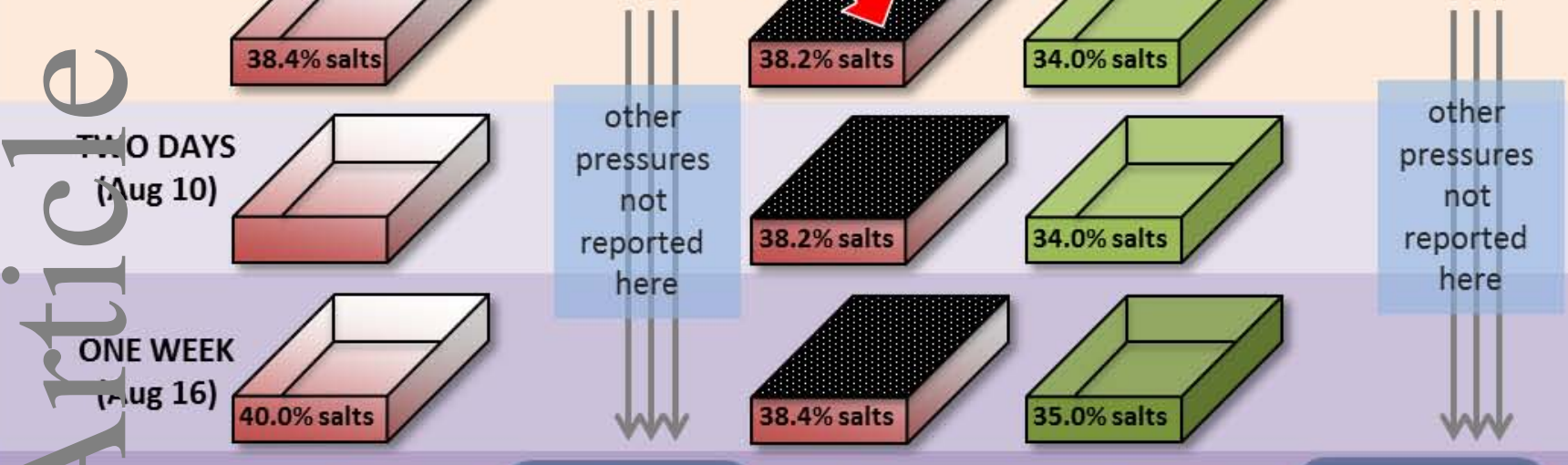

ONL MONTH

(Sep 6)
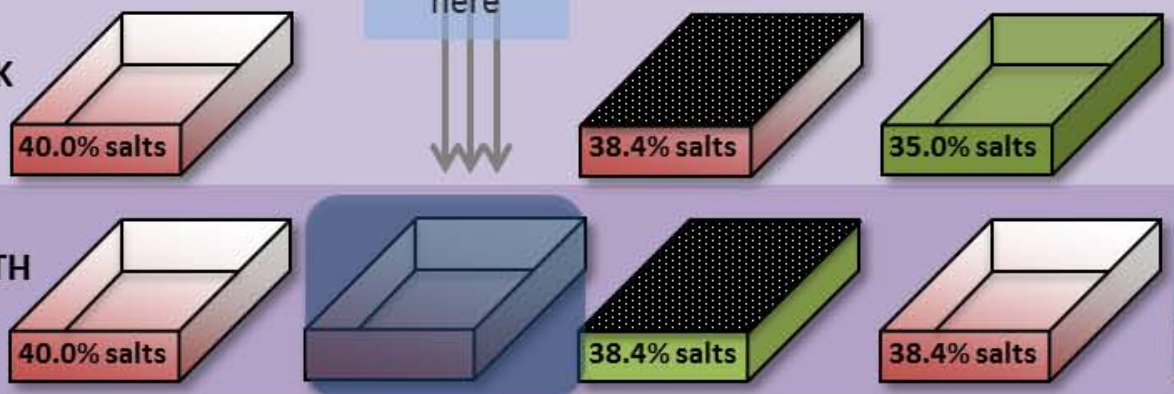

here
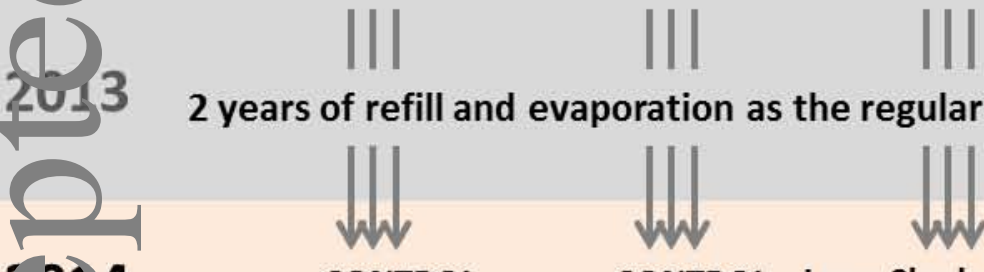

20) 4

CONTROL

(E1)

CONTROL Long-Shaded-2014

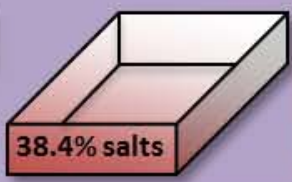

III

II

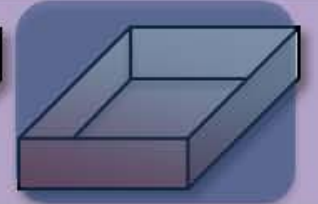

() ZERO

CAug 6)

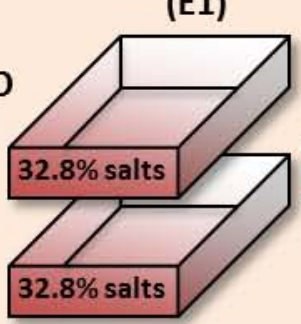

TWO DAYS

(Aug 8)
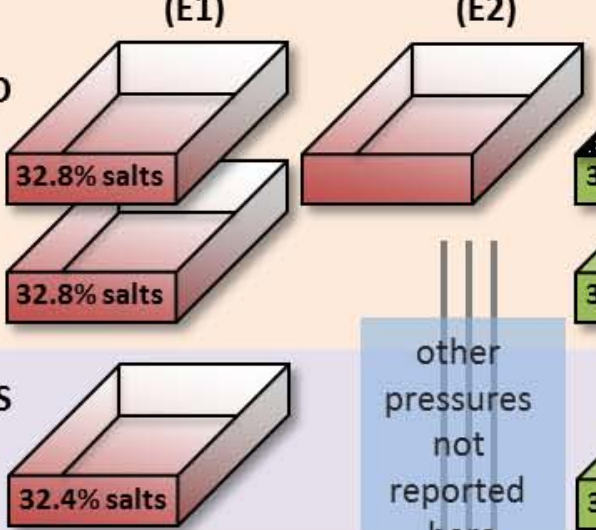

(E4)

HI-shaded

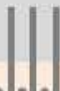

CONTROL

(E6)

(E5)
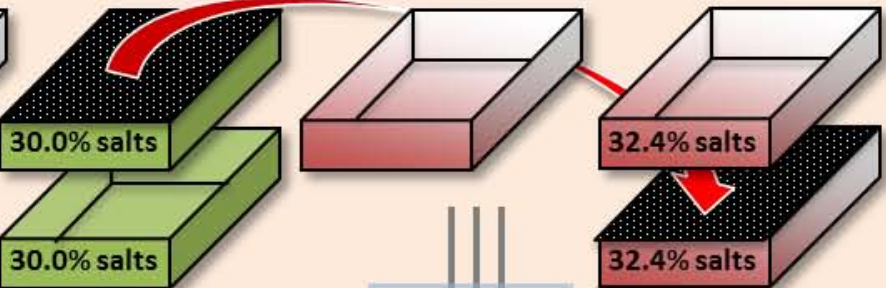

other

pressures

not

reported

here

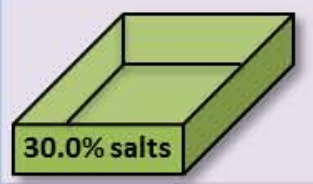

ONE WEEK
(Aug 11)
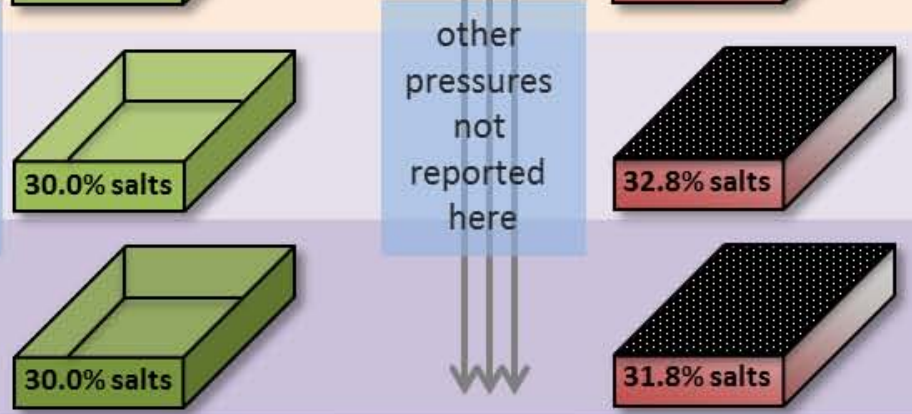

ONE MONTH

(Sep 3)
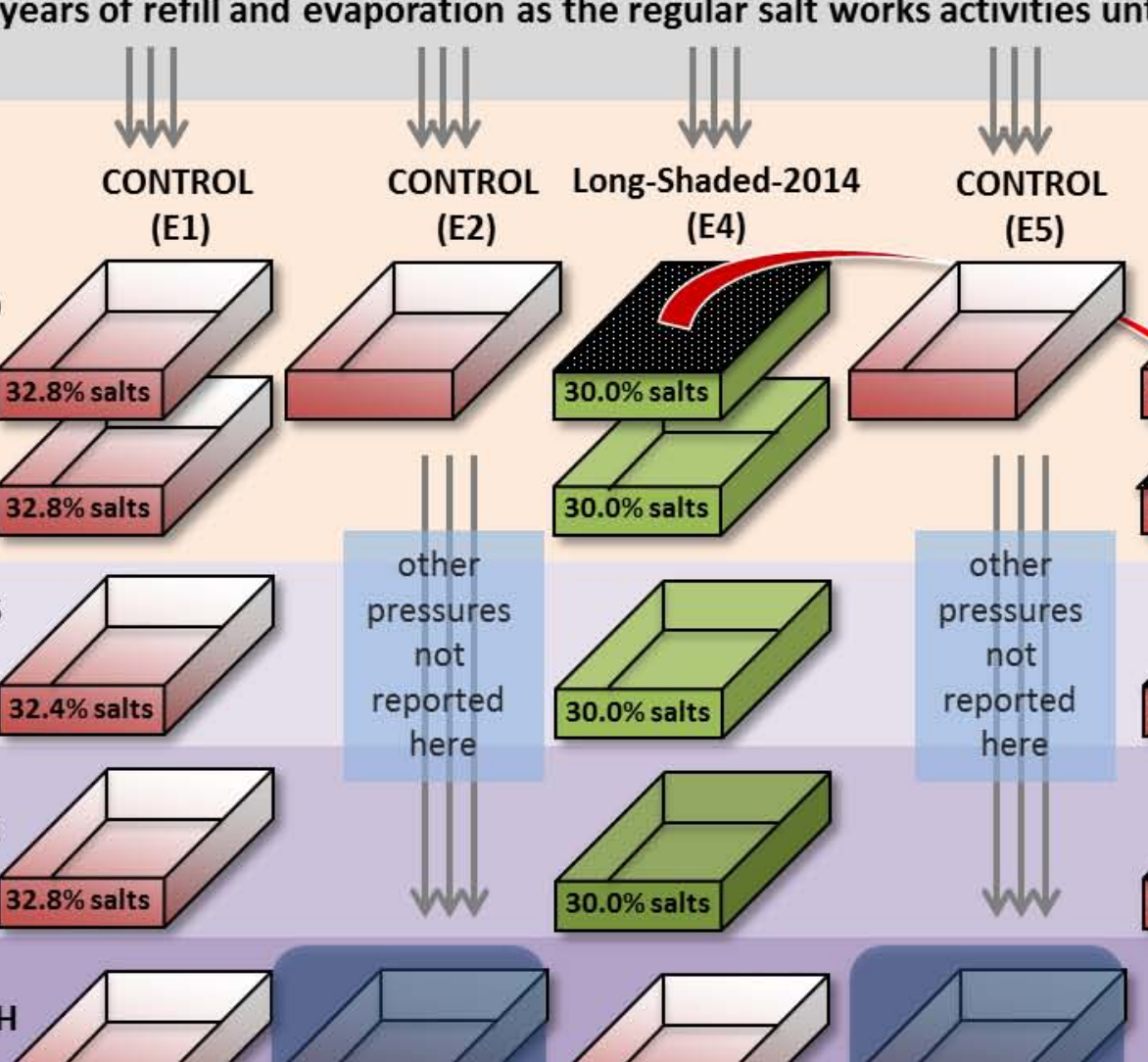

2014 


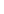


- Control Pond

$\triangle$ Short - Shaded Pond

Shaded E4 Pond

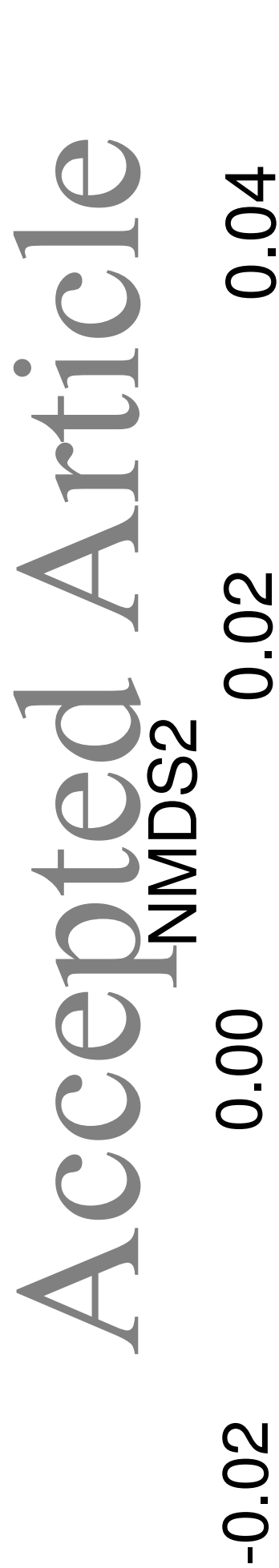

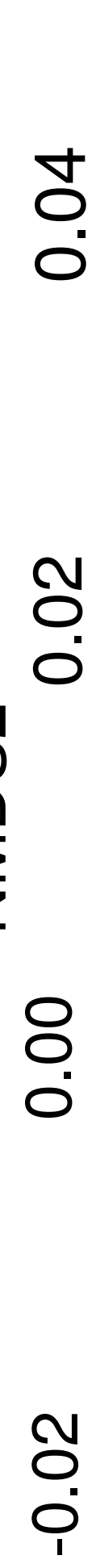

A

1 month

0 hours

1 month

1 day

1 week

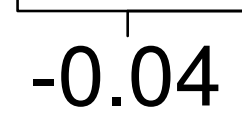

$-0.02$
2 days

0 hours $\triangle$

$\triangle 1$ month

0 hours

1 day

2 days

NMDS1
- Control Pond

$\triangle$ Long - Shaded Pond

Shaded E6 Pond

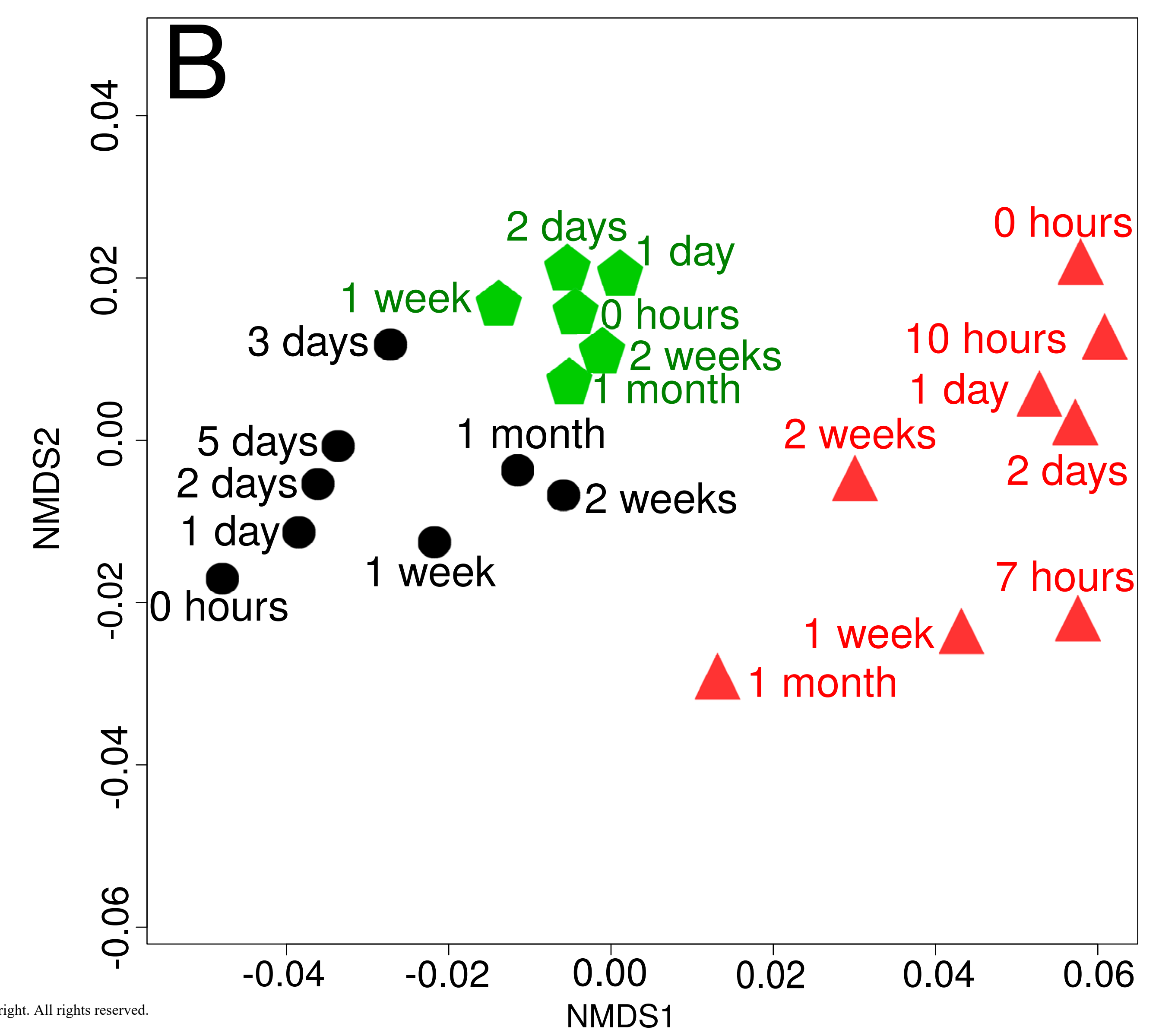




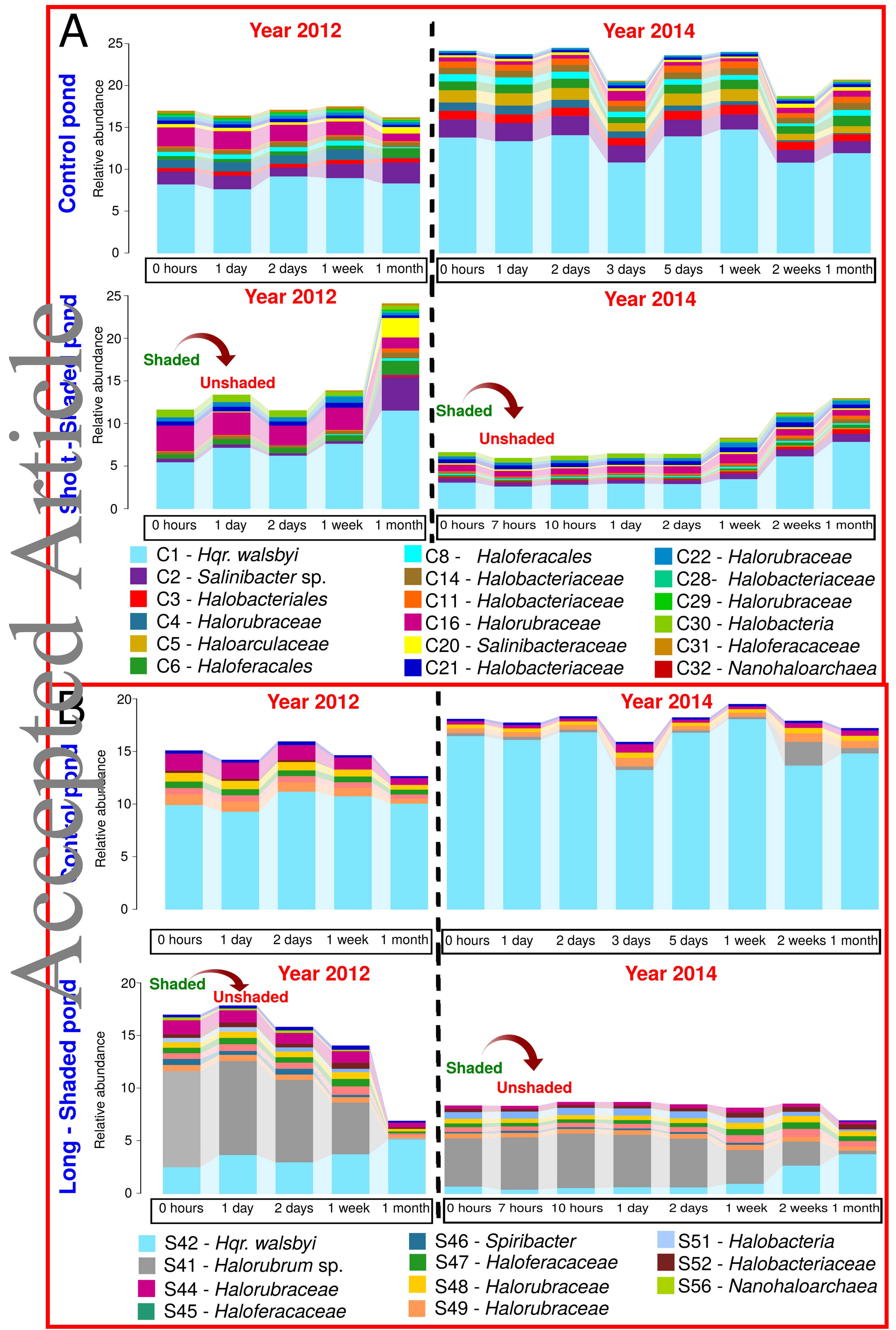


A

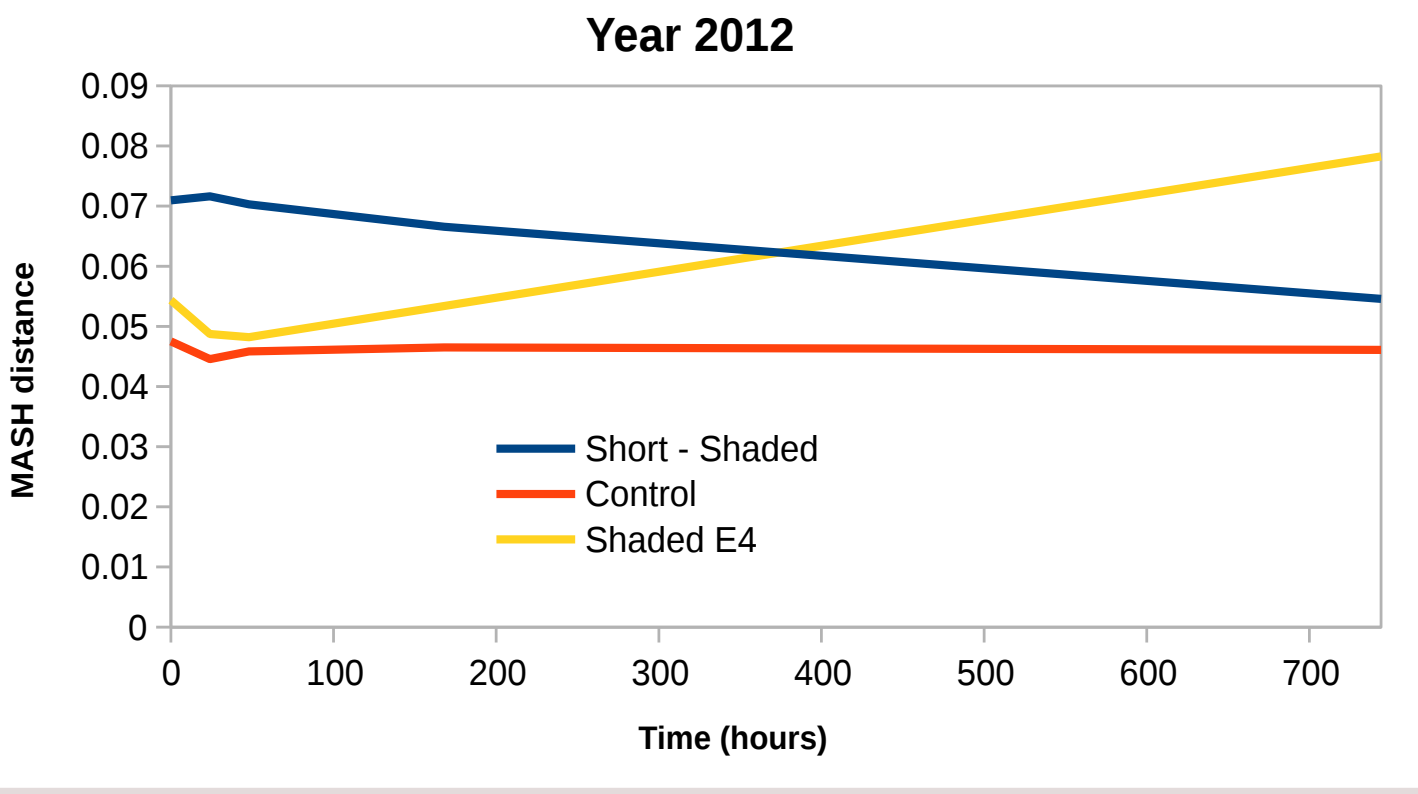

C

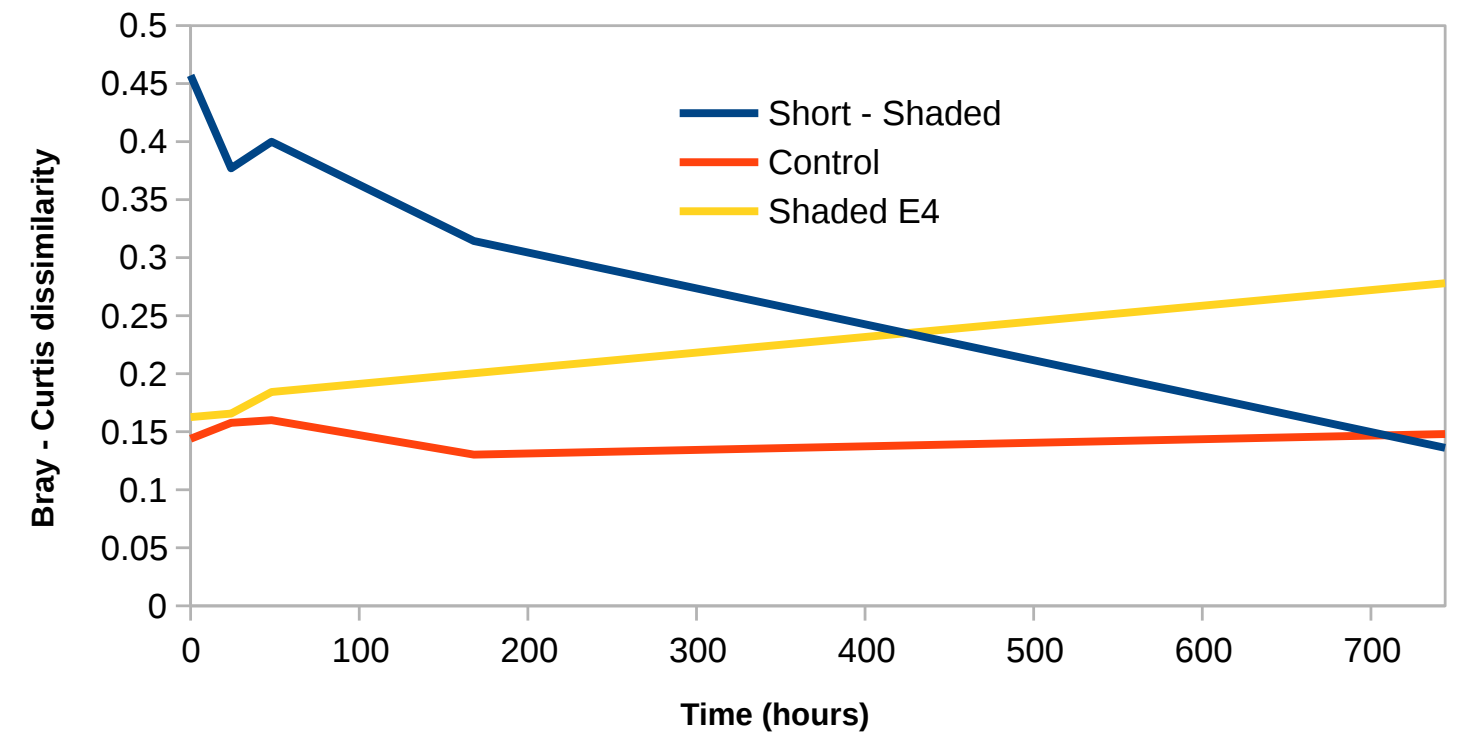

B

Year 2014

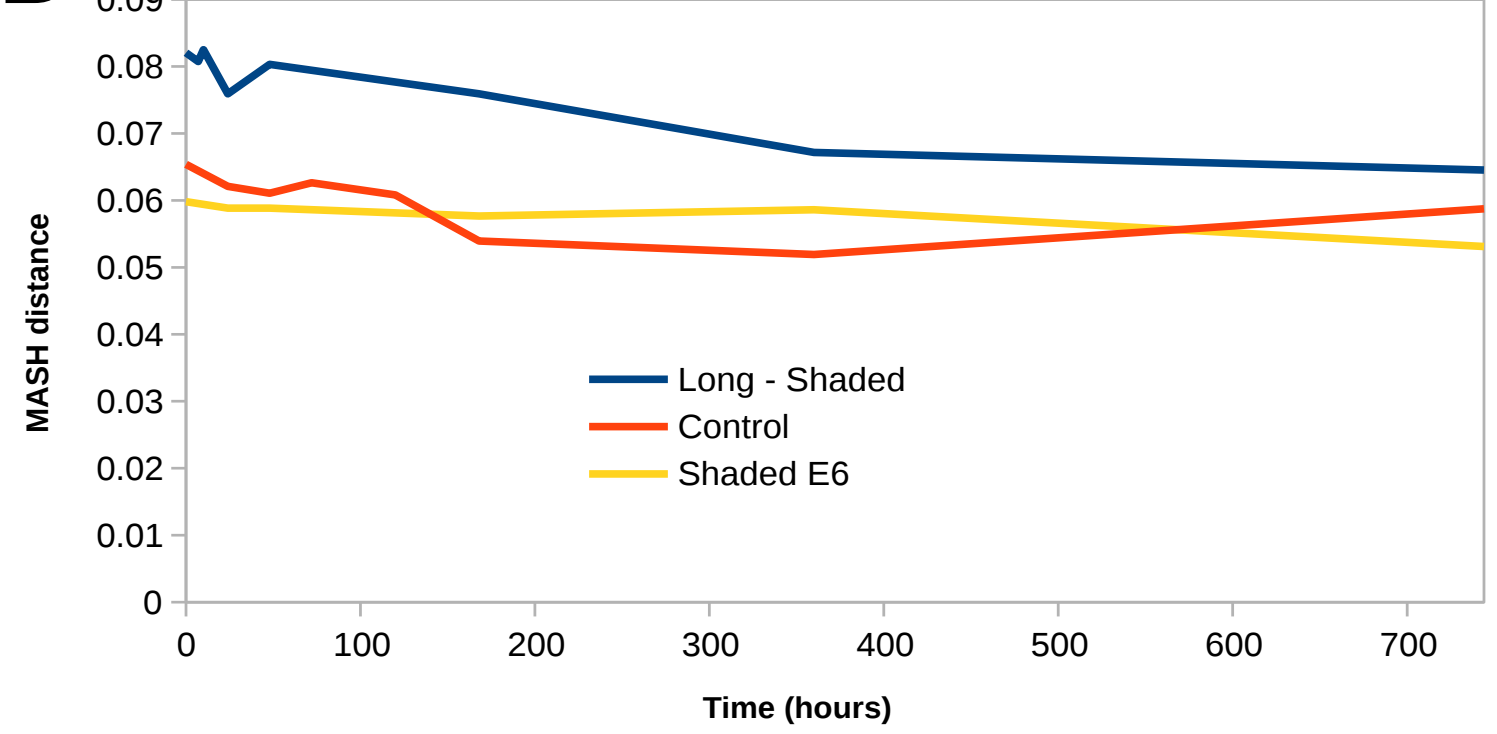

D

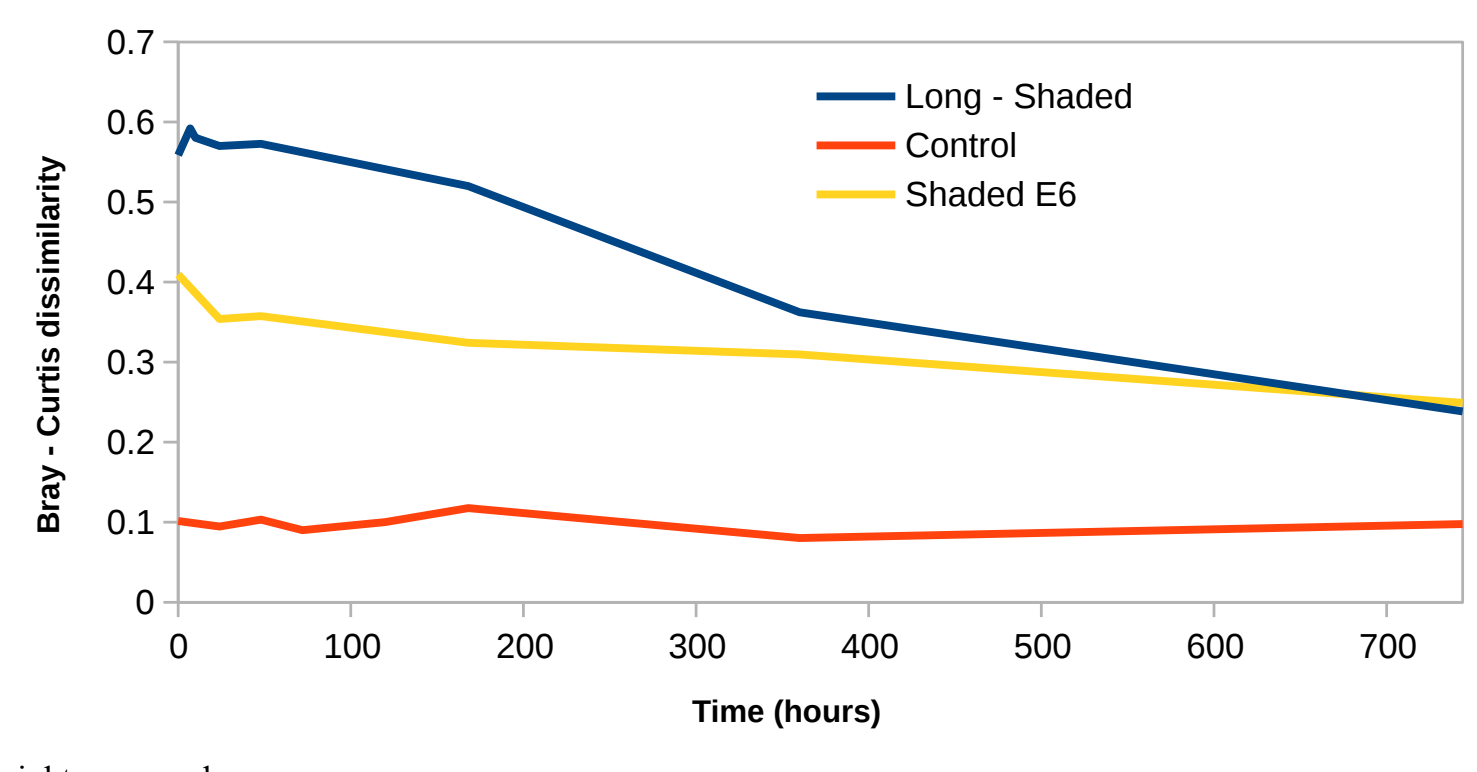




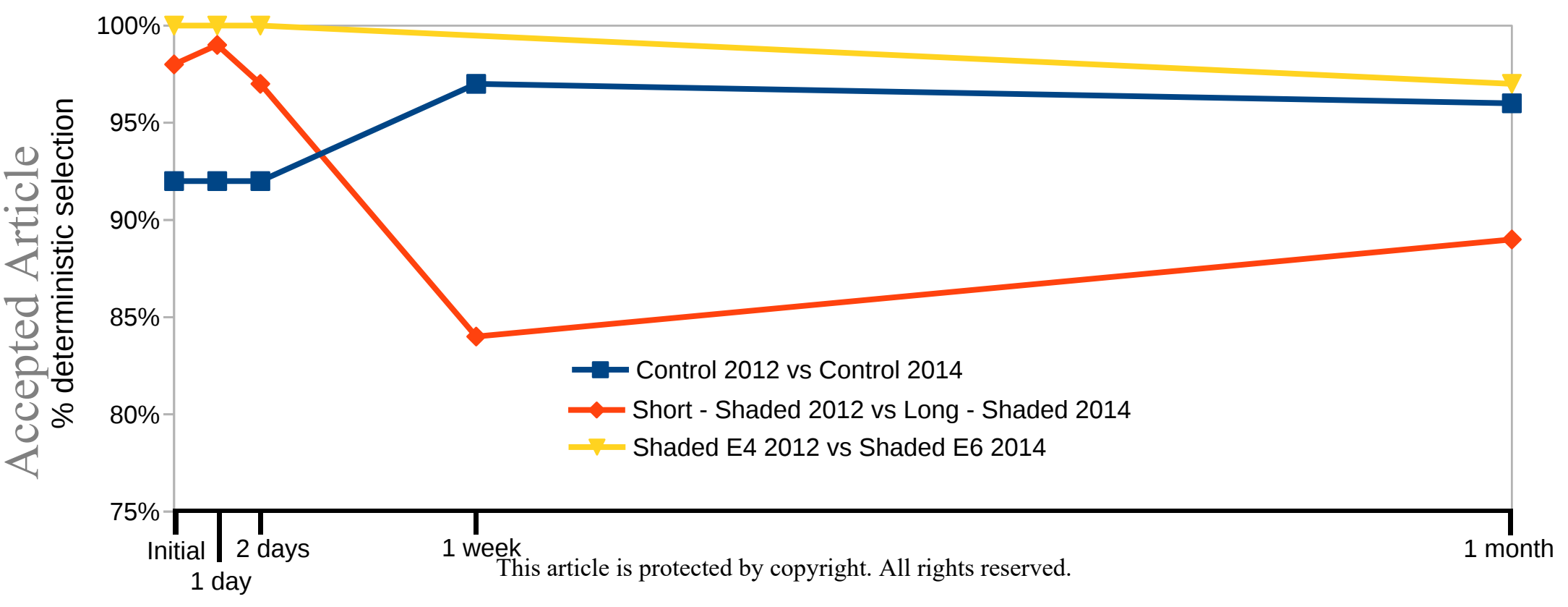


Table 1

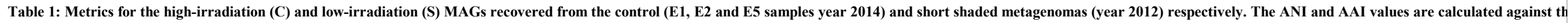

\begin{tabular}{|c|c|c|c|c|c|c|c|c|c|c|}
\hline & MAG & Num. Contigs & Bases & $\% G C$ & Longest contig & Completeness & Contamination & Reference genome (Genome acc. nr.) & ANI (num. Genes shared) & AAI (numb. Proteins shared) \\
\hline \multirow{18}{*}{ 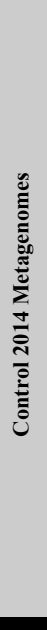 } & C1 & 542 & $1,494,937$ & 47.94 & 10.985 & 57.7 & 0.0 & Haloquadratum walsbyi DSM 16790 (FR746099.1) & $99.83 \%(1,040)$ & $97.95 \%(1300)$ \\
\hline & C2 & 874 & $2,130,390$ & 64.86 & 25.993 & 88.88 & 2.03 & Salinibacter ruber DSM 13855 (СР000159.1) & $91.68 \%(790)$ & $89.94(1,537)$ \\
\hline & C3 & 1.111 & $2,046,287$ & 62.27 & 26.887 & 26.9 & 0.0 & Halonotius J07HN4 (AGCX01) & $88.62 \%(351)$ & $80.45 \%(1289)$ \\
\hline & C4 & 502 & $2,311,085$ & 67.36 & 45.253 & 69.28 & 7.7 & Halophilic archaeon J07HB67 (AGCZ00000000.1) & $88.27 \%(567)$ & $82.36 \%(1553)$ \\
\hline & C5 & 765 & $3,292,633$ & 63.72 & 42.78 & 91.59 & 13.59 & Halophilic archaeon J07HX64 (AGCY00000000.1) & $88.62 \%(1280)$ & $85.3 \%(1880)$ \\
\hline & C6 & 286 & $2,711,051$ & 50.83 & 53.313 & 88.88 & 2.03 & Haloquadratum J07HQX50 (ARPZ00000000.1) & $96.09 \%(766)$ & $92.14 \%(1007)$ \\
\hline & C8 & 647 & $2,324,164$ & 64.51 & 27.156 & 53.99 & 11.5 & Halophilic archaeon J07HB67 (AGCZ00000000.1) & $87.41 \%(263)$ & $67.56(1169)$ \\
\hline & C11 & 1.075 & $2,862,627$ & 69.79 & 22.297 & 87 & 4.3 & Haloarcula vallismortis (AOLQ00000000.1) & $77.58 \%(346)$ & $61.31 \%(1796)$ \\
\hline & C14 & 487 & $1,267,342$ & 69.79 & 16.513 & 52.93 & 8.82 & Halonotius J07HN4 (AGCX01) & Insufficient hits & $55.52 \%(781)$ \\
\hline & C16 & 548 & $2,740,940$ & 69.79 & 39.439 & 46.2 & 3.8 & Halorubrum coriense DSM 10284 (AOJL00000000.1) & $92.75 \%(1613)$ & $90.71 \%(2283)$ \\
\hline & C20 & 1.149 & $2,253,197$ & 63.52 & 10.279 & 59.17 & 25.69 & Salinibacter ruber DSM 13855 (СР000159.1) & $83.11 \%(332)$ & $73.22 \%(1221)$ \\
\hline & C21 & 898 & $2,240,228$ & 61.74 & 21.999 & 43.5 & 8.7 & Natronomonas moolapensis(HF582854.1) & $82.64 \%(239)$ & $65.06 \%(1036)$ \\
\hline & C22 & 1.113 & $2,115,277$ & 66.91 & 10.275 & 34.6 & 0.0 & Halobellus rufus (BВJO00000000.1) & $81.67 \%(314)$ & $50.47 \%(232)$ \\
\hline & C28 & 437 & 838.951 & 68.51 & 8.768 & 28.62 & 3.8 & Natronomonas moolapensis 8811 (NC020388) & Insufficient hits & $60.44(58.54 \%)$ \\
\hline & C29 & 246 & 640.058 & 65.79 & 13.944 & 18.48 & 0.0 & Haloplanus natans DSM 17983 (ATYM00000000.1) & $86.83 \%(263)$ & $73.42 \%(609)$ \\
\hline & C30 & 662 & 871.016 & 64.67 & 3.297 & 23.49 & 3.45 & Hrr. trapanicum (AP017569) & Insufficient hits & $46.36(47.87 \%)$ \\
\hline & C31 & 389 & 922.217 & 68.93 & 10.156 & 29.91 & 1.87 & Haloferax volcanii DS2 (NC013967) & Insufficient hits & $62.52(67.24 \%)$ \\
\hline & C32 & 195 & $1,081,558$ & 43.49 & 56.825 & 91.3 & 13 & Candidatus Haloredivivus (AGNT00000000.1) & Insufficient hits & $70.1 \%(62)$ \\
\hline \multirow{12}{*}{ 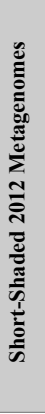 } & S41 & 115 & $1,269,037$ & 64.6 & 98.383 & 69.6 & 4.3 & Halorubrum coriense DSM 10284 (AOJL00000000.1) & Insufficient hits & $55.47 \%(1180)$ \\
\hline & S42 & 575 & $2,733,631$ & 48.4 & 33.829 & 100 & 2.49 & Haloquadratum walsbyi DSM 16790 (FR746099.1) & $99.76 \%(2248)$ & $98.81 \%(2114)$ \\
\hline & S44 & 369 & $2,855,681$ & 70.8 & 94.3 & 95.7 & 13 & Halorubrum coriense DSM 10284 (AOJL00000000.1) & $93.02 \%(2099)$ & $91.62 \%(2408)$ \\
\hline & S45 & 785 & $2,945,723$ & 66.9 & 25.385 & 82.6 & 0 & Halobellus rufus (BBJO00000000.1) & $81.28 \%(778)$ & $72.84 \%(1569)$ \\
\hline & S46 & 458 & $2,239,451$ & 64.7 & 97.32 & 95.1 & 0 & Spiribacter salinus M19-40 (СР005963.1) & $78.44 \%(425)$ & $73.47 \%(1476)$ \\
\hline & S47 & 696 & $2,054,025$ & 69.4 & 19.756 & 17.4 & 4.3 & Halobellus rufus (BВJO00000000.1) & $80.30 \%(434)$ & $70.98 \%(1283)$ \\
\hline & S48 & 1.067 & $2,725,400$ & 63.04 & 27.558 & 43.5 & 8.7 & Halobellus rufus (BBJO00000000.1) & $81.24(310)$ & $63.02 \%(1352)$ \\
\hline & S49 & 1.295 & $3,121,682$ & 66.5 & 20.234 & 91.3 & 0 & Halorubrum coriense DSM 10284 (AOJL00000000.1) & $77.91 \%(354)$ & $64.85 \%(1848)$ \\
\hline & S51 & 764 & $1,896,186$ & 64.7 & 26.67 & 39.1 & 0 & Halobellus rufus (BBJO00000000.1) & $76.34 \%(104)$ & $55.1 \%(1257)$ \\
\hline & 552 & 795 & $3,164,240$ & 63.5 & 31.399 & 91.3 & 0 & Natronomonas moolapensis (HF582854.1) & $80.9 \%(675)$ & $73.6 \%(1858)$ \\
\hline & S54 & 1.433 & $2,829,966$ & 39.53 & 55.398 & 54.9 & 1 & Psychroflexus salarius (FQTW00000000.1) & Insufficient hits & $56.57 \%(1438)$ \\
\hline & S56 & 1.294 & $3,253,065$ & 46.15 & 50.61 & 95 & 0 & Candidatus Haloredivivus (AGNT00000000.1) & Insufficient hits & $57.58 \%(688)$ \\
\hline
\end{tabular}

This article is protected by copyright. All rights reserved. 
